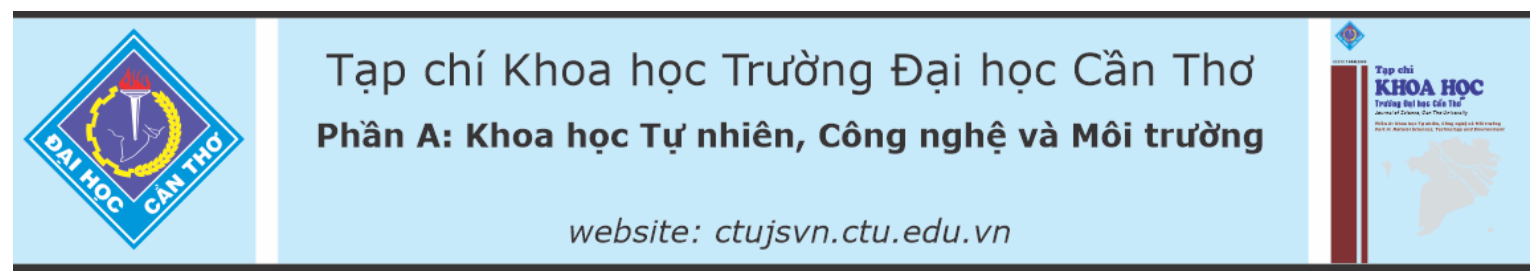

DOI:10.22144/ctu.jvn.2021.174

\title{
HỆ PHÂN PHỐI MỚI CHO THUỐC KHÁNG VIÊM KHÔNG STEROID (NSAID)
}

\author{
Phạm Cảnh Em* \\ Khoa Dược, Trường Đại học Quốc tế Hồng Bàng \\ *Người chịu trách nhiệm về bài viêt: Phạm Cảnh Em (email: empc@hiu.vn)
}

\section{Thông tin chung:}

Ngày nhận bài: $23 / 06 / 2021$

Ngày nhận bài sủa: 28/07/2021

Ngày duyệt đăng: 25/12/2021

\section{Title:}

New drug delivery systems for non-steroidal anti-

inflammatory drugs (NSAIDs)

\section{Tù khóa:}

Hạt nano, phân phối thuốc, thuốc kháng viêm không steroid, vi cầu

\section{Keywords:}

Drug deliver, microsphere, nanoparticle, non-steroidal anti-inflammatory drug

\begin{abstract}
Inflammatory processes are increasingly being identified at the core of many different disease states (e.g. heart disease, cancer, diabetes). While non-steroidal anti-inflammatory drugs are generally safe, there are some serious side effects that can be associated with their usage, particularly when given systemically or orally. Therefore, anti-inflammatory strategies available through drug delivery have undergone renewed interest. Novel drug delivery systems like systemic targeting or encapsulation, local injection, localized delivery, implant coating or incorporation, and transdermal delivery are promising tools as they have been successful in overcoming the disadvantages associated with conventional drug delivery systems like low solubility and permeability, poor bioavailability, degradation by gastrointestinal enzymes, first-pass metabolism, food interactions, and toxicity. This review comments on a sampling of existing methods for localized or targeted delivery of nonsteroidal anti-inflammatory drugs, with the goal of helping future research focus on bettering methods shown to be effective and filling the gaps of knowledge in this field.
\end{abstract}

\section{TÓM TẮT}

Quá trình viêm được xác định ngày càng rõ ràng là nguyên nhân cốt lõi của nhiều tình trạng bệnh khác nhau (ví dụ: bệnh tim, ung thu, tiểu đường). Mặc dù thuốc kháng viêm không steroid nhìn chung là an toàn nhung cũng có một số tác dụng phư nghiêm trọng liên quan đến đường sư dưng, đặc biệt khi đưa vào hẹ tuần hoàn hoặc sư dụng đường uống. Do đó, chiến luợc kháng viêm huớng muc tiêu hoạc sủ dụng hẹ phân phối thuốc nhận được sự quan tâm nghiên cưu hàng đầu. Các hệ phân phối thuốc mới nhu hệ hướng muc tiêu hoạc đóng gói, tiêm tại chố, phóng thích tại chỗ, lớp phủ hoạc kết hợp cấy ghép và hệ phân phối thuốc qua da là nhũng công cu đầy hứa hẹn vì khắc phục nhũng nhược điểm liên quan đến hẹ phân phối thuốc thông thường như độ hòa tan và tính thấm thấp, sinh khả dụng kém, bị phân hủy bởi các enzym tiêu hóa, chuyển hóa lần đầu, tương tác với thức ăn và độc tính. Đánh giá này nhận xét và tổng kết các phuoong pháp hiện có giúp phân phối thuốc kháng viêm không steroid tại chỗ hoạc hướng muc tiêu với muc đích hỗ trọ nghiên cưu trong tuơng lai tập trung vào các phương pháp thành công được chưng minh là có hiệu quả cao và lấp đầy khoảng trống kiến thức trong lĩnh vực này. 


\section{GIỚI THIẸU}

Có nhiều phương pháp khác nhau để điều trị viêm nhưng cho đến nay phổ biến nhất là sử dụng thuốc kháng viêm không steroid (non-steroidal anti-inflammatory drug, NSAID). Mỗi ngày trên toàn thế giới có khoảng 30 triệu người dùng thuốc NSAID. Thuốc NSAID được sử dụng trong điều trị viêm cấp tính, mãn tính và có hiệu quả cao trong phần lớn các trường hợp. Hơn 40 loại NSAID khác nhau đã được khám phá và chia thành nhiều loại khác nhau dựa trên cấu trúc và yếu tố nguy cơ. Phần lớn NSAID hấp thu hoàn toàn, ít chuyển hóa lần đầu qua gan, liên kết chặt chẽ với protein huyết thanh và có thể tích phân bố nhỏ. Thuốc NSAID khác nhau về thời gian bán hủy, con đường hấp thu và khả năng dung nạp. Thuốc NSAID trong cùng một nhóm sẽ có các đặc tính tương đồng nhau. Diclofenac và ibuprofen là những NSAID được sử dụng rộng rãi nhất trên thế giới. Theo sau là naproxen, indomethacin, piroxicam và ketoprofen. Thuốc ibuprofen, naproxen và aspirin là thuốc không cần kê đơn và được sử dụng trong điều trị nhiều trường hợp đau từ đau đầu đến đau sau phẫu thuật. Tuy nhiên, phần lớn NSAID được sử dụng trên toàn cầu đều được kê đơn trong chăm sóc sức khỏe ban đầu (Badri et al., 2016).

Khi mô gặp tổn thương (nhiễm trùng hoặc chấn thương), cơ thể sẽ phản ứng bằng cách khởi động quá trình viêm. Trong hầu hết các trường hợp, tình trạng viêm là một điều tốt vì giúp giải quyết được tổn thương bao gồm việc loại bỏ kích thích gây tổn thương và thay thế mô tổn thương bằng mô bình thường. Bạch cầu trung tính được huy động ngay lập tức, tiếp theo là đại thực bào và bạch cầu đơn nhân trong những ngày tiếp theo và cuối cùng là tế bào lympho và tế bào huyết tương để tái tạo mô. Tuy nhiên, có một số trường hợp viêm cấp tính chuyển thành viêm mãn tính hoặc viêm cấp tính không mong muốn (thường do đau dữ dội và mất chức năng). Trong những trường hợp này, NSAID có thể được sử dụng để giảm hoặc ngăn chặn quá trình viêm, để tăng chất lượng cuộc sống hoặc chữa lành vết thương (Badri et al., 2016).

Dù là loại thuốc nào thì tất cả NSAID đều có cùng một cơ chế hoạt động là giảm lượng prostaglandin. Prostaglandin thúc đẩy quá trình viêm thông qua điều chỉnh sự giãn mạch, kết tập tiểu cầu và được tìm thấy trong hầu hết mô của con người. Có nhiều loại prostaglandin và việc sản xuất prostaglandin được xúc tác bởi hai dạng enzym cyclooxygenase (COX): $\mathrm{COX}-1$ và $\mathrm{COX}-2$ (Badri et al., 2016).
NSAID hoạt động như chất ức chế thuận nghịch đối với enzym COX, liên kết với phân tử arginin phân cực, được tìm thấy ở cả hai dạng $\mathrm{COX}$ và ức chế chức năng enzym thông qua sự cản trở không gian. Sự ức chế này làm giảm mức độ sản xuất prostaglandin, do đó làm giảm đau và sốt. Prostaglandin được sản xuất bởi enzym COX-1, có chức năng hỗ trợ đông máu và bảo vệ niêm mạc dạ dày tránh môi trường acid cao. Việc ức chế enzym COX-1 và làm mất các chức năng điều tiết này, gây ra các tác dụng phụ không mong muốn liên quan đến việc sử dụng NSAID như loét dạ dày và chảy máu dạ dày (Hawkey, 2001).

Các NSAID hướng mục tiêu chọn lọc COX-2 đã được phát triển. Vị trí hoạt động của COX-2 lớn hơn so với COX-1, cho phép đạt được tính chọn lọc thông qua việc sử dụng các loại thuốc cồng kềnh để tiếp cận arginin phân cực trong COX-1. Tuy nhiên, chỉ có celecoxib là loại thuốc ức chế enzym COX-2 chọn lọc duy nhất được bán hoặc sử dụng trên thị trường dược phẩm tại Hoa Kỳ. Các loại thuốc chọn lọc COX-2 được phát triển trước đây chẳng hạn như rofecoxib và valdecoxib đã bị rút khỏi thị trường do tăng nguy cơ đau tim và đột quỵ tiến triển khi sử dụng lâu dài (toàn thân). Do đó, đại đa số bệnh nhân được dùng NSAID không chọn lọc và dùng bằng đường uống. Khi dùng toàn thân, NSAID không chọn lọc thường gây ra nhiều tác dụng phụ như buồn nôn, nôn, đau bụng, ợ chua, chóng mặt và nhức đầu. Các tác dụng phụ nghiêm trọng hơn liên quan đến NSAID là đau tim, đột quỵ, loét dạ dày và chảy máu dạ dày. Những tác dụng phụ này xảy ra do lượng prostaglandin bị giảm trong toàn bộ cơ thể, ở cả những mô đang biểu hiện viêm và những mô không bị viêm. Các tác dụng phụ ít phổ biến nhưng đe dọa tính mạng nhiều hơn, chúng là mối quan tâm đáng kể đối với những bệnh nhân đã mắc bệnh tim hoặc sức khỏe kém (Badri et al., 2016).

Do những tác dụng phụ này, gần đây đã có xu hướng rời bỏ việc sử dụng NSAID tác dụng toàn thân. Các loại thuốc kháng viêm khác chẳng hạn như các phân tử nhỏ có nguồn gốc tự nhiên đang được khám phá để sử dụng rộng rãi. Liệu pháp thay thế này có nhiều cơ chế để giảm thiểu tình trạng viêm nhưng cũng đi kèm với các tác dụng phụ. Do đó, sẽ thuận lợi và hợp lý hơn nếu tập trung vào cải thiện phương pháp điều trị với NSAID hiện có vì chúng thường có hiệu quả cao. Sử dụng hệ phân phối thuốc (tăng tác dụng, hướng mục tiêu) là phương pháp thay thế hấp dẫn nhằm kiểm soát phóng thích NSAID. Thuốc có thể được cung cấp tại chỗ, chỉ đạt đến nồng độ điều trị tại nơi được tiêm hoặc cấy vào cơ thể. Điều này giúp giảm đáng kể tác dụng phụ. 
Trong trường hợp thuốc NSAID, điều này có lợi khi không làm tăng acid dịch vị hay làm giảm chất nhầy gây loét dạ dày vì hệ phân phối chỉ phóng thích thuốc ở nơi cần tác động. Hệ phân phối thuốc có thể lưu thông khắp toàn bộ cơ thể nhưng không gây tác dụng phụ tại vị trí không mong muốn, ví dụ như dạ dày do thuốc NSAID được bao bọc bởi phương tiện phóng thích và hạn chế thuốc tiếp xúc trực tiếp với các vị trí không phải mục tiêu (Badri et al., 2016).

Nếu NSAID có thể được phân phối theo cách thông minh hơn, thông qua hệ phân phối thuốc thì các tác dụng phụ toàn thân liên quan đến NSAID sẽ giảm đáng kể hoặc có thể hoàn toàn loại bỏ. Có nhiều nhóm nghiên cứu đã thực hiện thành công mục tiêu sử dụng hệ phân phối thuốc NSAID, nghiên cứu này sẽ tổng kết những phương pháp nồi bật và thành công trong thời gian từ 1995 đến nay. Với thông tin này, hy vọng rằng các nhóm nghiên cứu sẽ điều chỉnh các thử nghiệm trong tương lai để lấp đầy khoảng trống kiến thức trong lĩnh vực này.

\section{HÊ PHÂN PHỐI NSAID HƯỚNG MỤC TIÊU}

\subsection{Phương tiện phóng thích}

Các nghiên cứu đã thực hiện khảo sát phóng thích NSAID từ nhiều loại phương tiện khác nhau. Đối với đánh giá này, phương tiện phóng thích được chia thành năm loại: hệ hướng mục tiêu hoặc đóng gói, tiêm tại chỗ, phóng thích tại chỗ, lớp phủ hoặc kết hợp cấy ghép và hệ phân phối thuốc qua da. Các loại được chia theo nguyên nhân và bệnh viêm, từ cấy ghép y sinh đến viêm xương khớp và chữa lành vết thương. Mỗi phương tiện đều có những ưu điểm, nhược điểm riêng và hỗ trợ cho một số phương pháp điều trị bệnh nhất định.

\subsection{Hệ hướng mục tiêu hoặc đóng gói}

Hệ thống phóng thích là quản lý thuốc hấp thu vào hệ tuần hoàn, do đó toàn bộ cơ thể sẽ bị ảnh hưởng. Đây là phương pháp hiện đang được sử dụng cho hầu hết phương pháp điều trị NSAID. Hấp thu truyền thống qua hệ tuần hoàn có thể được cải thiện bằng phương pháp giới hạn khu vực hướng mục tiêu hoặc đóng gói thuốc, nhằm mục đích chỉ cho phép thuốc tác động ở những vị trí cụ thể, từ đó giảm tác dụng phụ ở những vùng cơ thể không có mục tiêu (Bảng 1). Uu điểm chính của hướng mục tiêu, đóng gói là tạo một rào cản bổ sung giữa thuốc và niêm mạc dạ dày. Rào cản này phục vụ một mục đích kép. Nó bảo vệ thuốc khỏi sự phân hủy trong dạ dày và tác dụng tối đa trong quá trình trao đổi chất lần đầu, làm tăng sinh khả dụng của thuốc (Shi et al., 2017). Hệ thống hướng mục tiêu cũng bảo vệ dạ dày khỏi thuốc, làm giảm tác dụng phụ mà thuốc gây ra tại vị trí đó. Trong trường hợp NSAID, tác dụng phụ giảm ở dạ dày là điều đặc biệt thuận lợi vì giúp giảm loét dạ dày và chảy máu nhiều do sử dụng NSAID.

Ngay cả khi có rào cản này, NSAID cũng sẽ đi khắp cơ thể và có thể ảnh hưởng đến các khu vực hiện không bị viêm. Mặc dù hướng mục tiêu và đóng gói có thể làm giảm các tác dụng ngoài mục tiêu, tuy nhiên hệ thống phóng thích loại này vẫn chưa loại bỏ hoàn toàn tác dụng phụ liên quan đến hệ thống hấp thu. Các phương pháp được liệt kê trong bài đánh giá này là tất cả phương pháp cải tiến và phần lớn đang trong giai đoạn phát triển sớm với các thử nghiệm đặc tính ban đầu và một số thử nghiệm in vivo (Shi et al., 2017).

Bảng 1. Một số hệ phân phối thuốc NSAID

\begin{tabular}{|c|c|c|c|c|c|c|}
\hline & $\begin{array}{l}\text { Loại } \\
\text { phương tiện }\end{array}$ & Nguyên liệu & NSAID & $\begin{array}{l}\text { Thò̀i gian } \\
\text { phóng thích }\end{array}$ & Điều trị & $\begin{array}{l}\text { Tài liệu } \\
\text { tham khảo }\end{array}$ \\
\hline \multirow[t]{6}{*}{$\begin{array}{l}\text { Hệ thống } \\
\text { hướng mục } \\
\text { tiêu/ đóng gói }\end{array}$} & Hydrogel & $\begin{array}{l}\text { Carrageenan- } \\
\text { PAA }\end{array}$ & Diclofenac & $>24 \mathrm{~h}$ & & $\begin{array}{l}\text { (Hosseinzade } \\
\mathrm{h}, 2011 \text { ) }\end{array}$ \\
\hline & Hydrogel & Chitosan & Diclofenac & 1 ngày & $\begin{array}{l}\text { Phân phối dạ } \\
\text { dày - ruột }\end{array}$ & $\begin{array}{l}\text { (Sharma et } \\
\text { al., 2014) }\end{array}$ \\
\hline & Hydrogel & Chitosan/PVA & Diclofenac & 1 ngày & & $\begin{array}{l}\text { Das \& } \\
\text { Subuddhi, } \\
2016)\end{array}$ \\
\hline & Aerogel & Pectin-zinc & Diclofenac & $7 \mathrm{~h}$ & & $\begin{array}{l}\text { (Tkalec et al., } \\
\text { 2016) }\end{array}$ \\
\hline & Hạt nano & PLGA/chitosan & Diclofenac & 7-9 ngày & & $\begin{array}{l}\text { (Khanal et } \\
\text { al., 2016) }\end{array}$ \\
\hline & Hạt (1 mm) & $\begin{array}{l}\text { PVA-g-PAAm, } \\
\text { sodium alginate }\end{array}$ & Diclofenac & $6 \mathrm{~h} 40^{\prime}$ & Đại tràng & $\begin{array}{l}\text { (Sanli et al., } \\
\text { 2007) }\end{array}$ \\
\hline
\end{tabular}




\begin{tabular}{|c|c|c|c|c|c|c|}
\hline & $\begin{array}{l}\text { Loại } \\
\text { phương tiện }\end{array}$ & Nguyên liệu & NSAID & $\begin{array}{l}\text { Thòi gian } \\
\text { phóng thích }\end{array}$ & Điều trị & $\begin{array}{l}\text { Tài liệu } \\
\text { tham khảo }\end{array}$ \\
\hline & $\begin{array}{l}\text { Vi cầu } \\
\text { micro }\end{array}$ & PVA/PAA & Diclofenac & $\sim \mathrm{h}$ & $\begin{array}{l}\text { Cung cấp } \\
\text { cho ruột }\end{array}$ & $\begin{array}{l}\text { (Kurkuri \& } \\
\text { Aminabhavi, } \\
\text { 2004) }\end{array}$ \\
\hline & Hạt & TSP-alginate & Diclofenac & & & $\begin{array}{l}\text { (Nayak \& } \\
\text { Pal, 2011) }\end{array}$ \\
\hline & $\begin{array}{l}\text { Hạt/ túi } \\
\text { micro }\end{array}$ & $\begin{array}{l}\text { Alginate-PLL, } \\
\text { PLGA }\end{array}$ & Ibuprofen & 14 ngày & & $\begin{array}{l}\text { (Baruch et } \\
\text { al., 2009) }\end{array}$ \\
\hline & Hạt nano & Chitosan/ $/ \mathrm{TiO}_{2}$ & Ibuprofen & $24-54 \mathrm{~h}$ & & $\begin{array}{l}\text { (Kamari \& } \\
\text { Ghiaci, 2016) }\end{array}$ \\
\hline & $\begin{array}{l}\text { PDC - cấu } \\
\text { trúc nano } \\
\text { micellar } \\
\end{array}$ & mPEG-PPF & Ibuprofen & 8 ngày & $\begin{array}{l}\text { Viêm khớp } \\
\text { và ung thư }\end{array}$ & $\begin{array}{l}\text { (Seetharaman } \\
\text { et al., 2017) }\end{array}$ \\
\hline & Hạt nano & Lipid rắn & Ibuprofen, & 6 ngày & & \multirow{3}{*}{$\begin{array}{l}\text { (Kumar et } \\
\text { al., 2018) }\end{array}$} \\
\hline & \multicolumn{5}{|c|}{ Ketoprofen, } & \\
\hline & \multicolumn{5}{|c|}{ Nabumetone } & \\
\hline & Hạt micro & Ethylcellulose & Ketoprofen & 1 ngày & & $\begin{array}{l}\text { (Yamada et } \\
\text { al., 2001) }\end{array}$ \\
\hline & $\begin{array}{l}\text { Phim/ thảm } \\
\text { sợi nano } \\
\text { electrospun }\end{array}$ & PVA & Ketoprofen & 14 ngày & & $\begin{array}{l}\text { (Kenawy et } \\
\text { al., 2007) }\end{array}$ \\
\hline & Tiền thuốc & $\begin{array}{l}\text { Saccharide biến } \\
\text { tính }\end{array}$ & Ketoprofen & > 10 ngày & & $\begin{array}{l}\text { (Wu et al., } \\
2010)\end{array}$ \\
\hline & $\begin{array}{l}\text { Hạt nano, } \\
\text { hydrogel }\end{array}$ & $\begin{array}{l}\text { Poly(mPEGMA- } \\
\text { co-MAA) }\end{array}$ & Meloxicam & $>72 \mathrm{~h}$ & $\begin{array}{l}\text { Viêm xương } \\
\text { khớp và viêm } \\
\text { khớp dạng } \\
\text { thấp }\end{array}$ & $\begin{array}{l}\text { (Shi et al., } \\
\text { 2017) }\end{array}$ \\
\hline & $\begin{array}{l}\text { Bọt biển } \\
\text { nano phân } \\
\text { hủy sinh học }\end{array}$ & $\beta$-cyclodextrin & Meloxicam & $>24 \mathrm{~h}$ & & $\begin{array}{l}\text { (Shende et } \\
\text { al., 2015) }\end{array}$ \\
\hline & $\begin{array}{l}\text { Viên nang } \\
\text { nano lipid }\end{array}$ & & Meloxicam & - & & $\begin{array}{l}\text { (Villalba et } \\
\text { al., 2016) }\end{array}$ \\
\hline & $\begin{array}{l}\text { Vi cầu } \\
\text { micro }\end{array}$ & $\begin{array}{l}\text { Hydroxypropyl } \\
\text { cyclosophoraose- } \\
\text { pullulan }\end{array}$ & Naproxen & 3 ngày & & $\begin{array}{l}\text { (Choi et al., } \\
\text { 2017) }\end{array}$ \\
\hline & Micelle & $\begin{array}{l}\text { Đồng polymer } \\
\text { mPEG-PCL }\end{array}$ & Naproxen & 3 ngày 4 h & & $\begin{array}{l}\text { (Karami et } \\
\text { al., 2016) }\end{array}$ \\
\hline & Ống nano & Silica & Naproxen & $50 \mathrm{~h}$ & $\begin{array}{l}\text { Viêm mãn } \\
\text { tính }\end{array}$ & $\begin{array}{l}\text { (Sousa et al., } \\
2012 \text { ) }\end{array}$ \\
\hline & Sol-gel & $\begin{array}{l}\text { Zirconium(IV) } \\
\text { propoxide/ } \\
\text { tetraethyl } \\
\text { orthosilicate, } \\
\text { chitosan }(\mathrm{TECN}) \\
\text { và MC@Z) }\end{array}$ & Naproxen & $>24 \mathrm{~h}$ & & $\begin{array}{l}\text { (Ghazaie et } \\
\text { al., 2017) }\end{array}$ \\
\hline Tiêm cục bộ & Liên hợp & PEG & Diclofenac & > 100 ngày & $\begin{array}{l}\text { Viêm xương } \\
\text { khớp }\end{array}$ & $\begin{array}{l}\text { (Sulistio et } \\
\text { al., 2017) }\end{array}$ \\
\hline & Tiền thuốc & & Diclofenac & 2 ngày $7 \mathrm{~h}$ & $\begin{array}{l}\text { Viêm xương } \\
\text { khớp, chấn } \\
\text { thương }\end{array}$ & $\begin{array}{l}\text { (Thing et al., } \\
\text { 2014) }\end{array}$ \\
\hline & Gel & Poloxamer & Ibuprofen & 2 h $11^{\prime}$ & $\begin{array}{l}\text { Tiêm ngoài } \\
\text { màng cứng }\end{array}$ & $\begin{array}{l}\text { (Paavola et } \\
\text { al., 2016) }\end{array}$ \\
\hline & $\begin{array}{l}\text { Polymer } \\
\text { nhớt }\end{array}$ & PLG & Ketoprofen & 33 ngày & & $\begin{array}{l}\text { (Wang et al., } \\
\text { 2007) }\end{array}$ \\
\hline
\end{tabular}




\begin{tabular}{|c|c|c|c|c|c|c|}
\hline & $\begin{array}{l}\text { Loại } \\
\text { phương tiện }\end{array}$ & Nguyên liệu & NSAID & $\begin{array}{l}\text { Thời gian } \\
\text { phóng thích }\end{array}$ & Điều trị & $\begin{array}{l}\text { Tài liệu } \\
\text { tham khảo }\end{array}$ \\
\hline & Hạt nano & $\begin{array}{l}\text { Alginate/chitosan } \\
\text { / pluronic }\end{array}$ & Meloxicam & & $\begin{array}{l}\text { Viêm xương } \\
\text { khớp }\end{array}$ & $\begin{array}{l}\text { (Fattahpour } \\
\text { et al., 2015) }\end{array}$ \\
\hline \multirow[t]{16}{*}{$\begin{array}{l}\text { Phóng thích } \\
\text { cục bộ }\end{array}$} & Hydrogel & $\begin{array}{l}\text { PCLA-PEG- } \\
\text { PCLA }\end{array}$ & Celecoxib & $\begin{array}{l}100 \text { ngày (in } \\
\text { vitro), } 4-8 \\
\text { tuần (in } \\
\text { vivo) }\end{array}$ & $\begin{array}{l}\text { Viêm xương } \\
\text { khớp }\end{array}$ & $\begin{array}{l}\text { (Petit et al., } \\
\text { 2014) }\end{array}$ \\
\hline & Hạt micro & PLGA & Celecoxib & 60 ngày & $\begin{array}{l}\text { Bệnh tiểu } \\
\text { đường ở mắt }\end{array}$ & $\begin{array}{l}\text { (Amrite et } \\
\text { al., 2006) }\end{array}$ \\
\hline & $\begin{array}{l}\text { Màng cấu } \\
\text { trúc nano }\end{array}$ & $\begin{array}{l}\text { Poly }(N- \\
\text { methacryloyl } \\
\text { glycine }) / \text { nanocell } \\
\text { ulose vi khuẩn }\end{array}$ & Diclofenac & $4 \mathrm{~h}$ & $\begin{array}{l}\text { Phân phối } \\
\text { qua da và } \\
\text { đường uống }\end{array}$ & $\begin{array}{l}\text { (Saidi et al., } \\
\text { 2017) }\end{array}$ \\
\hline & Phim & PP & $\begin{array}{l}\text { Diclofenac, } \\
\text { Ibuprofen }\end{array}$ & h, 1 ngày & $\begin{array}{l}\text { Cấy ghép sửa } \\
\text { đổi }\end{array}$ & $\begin{array}{l}\text { (Melendez et } \\
\text { al., 2014) }\end{array}$ \\
\hline & Phim & PLGA & Ibuprofen & 10 ngày & & $\begin{array}{l}\text { (Pang et al., } \\
\text { 2011) }\end{array}$ \\
\hline & Màng sợi & PLGA & Ibuprofen & 70 ngày & $\begin{array}{l}\text { Hàng rào } \\
\text { chống dính } \\
\text { mô }\end{array}$ & $\begin{array}{l}\text { (Liu et al., } \\
\text { 2017) }\end{array}$ \\
\hline & $\begin{array}{l}\text { Vi cầu } \\
\text { micro }\end{array}$ & $\begin{array}{l}\text { PLGA/PVA/gelat } \\
\text { in }\end{array}$ & Ibuprofen & 63 ngày & $\begin{array}{l}\text { Viêm xương } \\
\text { khớp }\end{array}$ & $\begin{array}{l}\text { (Park et al., } \\
\text { 2016) }\end{array}$ \\
\hline & Ống micro & $\begin{array}{l}\text { Polycaprolactone } \\
\text { (PCL) }\end{array}$ & Ibuprofen & 30 ngày & $\begin{array}{l}\text { Tái tạo thần } \\
\text { kinh ngoại } \\
\text { biên (ống } \\
\text { dẫn hướng } \\
\text { thần kinh) }\end{array}$ & $\begin{array}{l}\text { (Salmoria et } \\
\text { al., 2016) }\end{array}$ \\
\hline & Hydrogel & $\begin{array}{l}\text { Sợi cellulose } \\
\text { nano anion }\end{array}$ & Ketoprofen & $>72 \mathrm{~h}$ & & $\begin{array}{l}\text { (Paukkonen } \\
\text { et al., 2017) }\end{array}$ \\
\hline & Hạt micro & PHB/chitosan & Ketoprofen & 2,5 ngày & & $\begin{array}{l}\text { (Lins et al., } \\
\text { 2015) }\end{array}$ \\
\hline & $\begin{array}{l}\text { Sợi nano } \\
\text { electrospun }\end{array}$ & PLA & Ketoprofen & 12,5 ngày & & $\begin{array}{l}\text { (Park \& Lee, } \\
2010)\end{array}$ \\
\hline & Màng & $\begin{array}{l}\text { Chất nền } \\
\text { polyurethan }\end{array}$ & Ketoprofen & $2 \mathrm{~h}$ & & $\begin{array}{l}\text { (Macocinschi } \\
\text { et al., 2012) }\end{array}$ \\
\hline & $\begin{array}{l}\text { Phim/ sợi } \\
\text { electrospun }\end{array}$ & $\begin{array}{l}\text { Chitosan/PVA/H } \\
\text { A }\end{array}$ & Meloxicam & 1 ngày & $\begin{array}{l}\text { Bệnh nha } \\
\text { khoa }\end{array}$ & $\begin{array}{l}\text { (Yar et al., } \\
2016)\end{array}$ \\
\hline & $\begin{array}{l}\text { Sợi nano } \\
\text { electrospun }\end{array}$ & PCL & Naproxen & & & $\begin{array}{l}\text { (Canbolat et } \\
\text { al., 2014) }\end{array}$ \\
\hline & $\begin{array}{l}\text { Vi cầu } \\
\text { micro }\end{array}$ & $\begin{array}{l}\text { Polyorganophosp } \\
\text { hazen }\end{array}$ & Naproxen & 33 ngày 8 h & $\begin{array}{l}\text { Bệnh nha } \\
\text { khoa }\end{array}$ & $\begin{array}{l}\text { (Veronese et } \\
\text { al., 1998) }\end{array}$ \\
\hline & $\begin{array}{l}\text { Thảm sợi } \\
\text { electrospun }\end{array}$ & $\begin{array}{l}\text { Chitosan/HA/PV } \\
\text { A }\end{array}$ & Piroxicam & $5 \mathrm{~h}$ & $\begin{array}{l}\text { Bệnh nha } \\
\text { khoa }\end{array}$ & $\begin{array}{l}\text { (Farooq et } \\
\text { al., 2015) }\end{array}$ \\
\hline \multirow[t]{4}{*}{$\begin{array}{l}\text { Lớp phủ/ kết } \\
\text { họ̣p cấy ghép }\end{array}$} & $\begin{array}{l}\text { Khung kỹ } \\
\text { thuật mô } \\
\text { xương }\end{array}$ & PLGA/PEG & Diclofenac & 60 ngày & $\begin{array}{l}\text { Gãy xương } \\
\text { và khuyết tật }\end{array}$ & $\begin{array}{l}\text { (Sidney et } \\
\text { al., 2015) }\end{array}$ \\
\hline & $\begin{array}{l}\text { Lớp phủ } \\
\text { aerogel }\end{array}$ & Pectin-Xanthin & $\begin{array}{l}\text { Diclofenac, } \\
\text { indomethacin }\end{array}$ & 1 ngày & $\begin{array}{l}\text { Cấy ghép } \\
\text { chỉnh hình }\end{array}$ & $\begin{array}{l}\text { (Horvat et } \\
\text { al., 2017) }\end{array}$ \\
\hline & Ống nano & $\mathrm{PLGA} / \mathrm{TiO}_{2}$ & Ibuprofen & 7 ngày & $\begin{array}{l}\text { Cấy ghép } \\
\text { titan }\end{array}$ & $\begin{array}{l}\text { (Jia \& Kerr, } \\
2013 \text { ) }\end{array}$ \\
\hline & $\begin{array}{l}\text { Vi cầu } \\
\text { micro } \\
\text { aerogel }\end{array}$ & Tinh bột PCL & Ketoprofen & 3 ngày & $\begin{array}{l}\text { Chỉnh sửa } \\
\text { xương }\end{array}$ & $\begin{array}{l}\text { (Goimil et } \\
\text { al., 2017) }\end{array}$ \\
\hline $\begin{array}{l}\text { Phóng thích } \\
\text { qua da và } \\
\text { cục bộ }\end{array}$ & Phim & $\begin{array}{l}\text { Polyox, } \\
\text { Carrageenan }\end{array}$ & Diclofenac & & & $\begin{array}{l}\text { (Boateng et } \\
\text { al., 2013) }\end{array}$ \\
\hline
\end{tabular}




\begin{tabular}{|c|c|c|c|c|c|}
\hline $\begin{array}{l}\text { Loại } \\
\text { phương tiện }\end{array}$ & Nguyên liệu & NSAID & $\begin{array}{l}\text { Thò̀i gian } \\
\text { phóng thích }\end{array}$ & Điều trị & $\begin{array}{l}\text { Tài liệu } \\
\text { tham khảo }\end{array}$ \\
\hline Màng & PVA/chitosan & Ibuprofen & 3 ngày & $\begin{array}{l}\text { Làm lành vết } \\
\text { thương }\end{array}$ & $\begin{array}{l}\text { (Morgado et } \\
\text { al., 2017) }\end{array}$ \\
\hline Hydrogel & Xanthan & Ibuprofen & $>12 \mathrm{~h}$ & & $\begin{array}{l}\text { (Djekic et al., } \\
2016)\end{array}$ \\
\hline Miếng dán & $\begin{array}{l}\text { Thuốc - chất kết } \\
\text { dính (MDIA) }\end{array}$ & Meloxicam & $>24 \mathrm{~h}$ & $\begin{array}{l}\text { Viêm xương } \\
\text { khớp }\end{array}$ & $\begin{array}{l}\text { (Ah et al., } \\
2010)\end{array}$ \\
\hline $\begin{array}{l}\text { Nanoethoso } \\
\text { me gel }\end{array}$ & Ethosome & Meloxicam & $>24 \mathrm{~h}$ & Phù nề & $\begin{array}{l}\text { (Ahad et al., } \\
\text { 2014) }\end{array}$ \\
\hline $\begin{array}{l}\text { Miếng dán } \\
\text { vi kim }\end{array}$ & $\begin{array}{l}\text { PVA phân tử } \\
\text { lượng thấp, } \\
\text { polyvinylpyrolido } \\
\text { ne }\end{array}$ & Meloxicam & $>24 \mathrm{~h}$ & Viêm khớp & $\begin{array}{l}\text { (Amodwala } \\
\text { et al., 2017) }\end{array}$ \\
\hline Hạt nano & Lipid rắn & Naproxen & $>24 \mathrm{~h}$ & & $\begin{array}{l}\text { (Akbari et } \\
\text { al., 2016) }\end{array}$ \\
\hline $\begin{array}{l}\text { Thảm điện } \\
\text { tử }\end{array}$ & TPU & Naproxen & Cấp tính & & $\begin{array}{l}\text { (Akduman et } \\
\text { al., 2014) }\end{array}$ \\
\hline $\begin{array}{l}\text { Thảm điện } \\
\text { tử }\end{array}$ & TPU & Naproxen & & & $\begin{array}{l}\text { (Akduman et } \\
\text { al., 2016) }\end{array}$ \\
\hline $\begin{array}{l}\text { Thảm sợi } \\
\text { nano điện tử }\end{array}$ & PVA & $\begin{array}{l}\text { Sodium } \\
\text { salicylate, } \\
\text { diclofenac, } \\
\text { naproxen, } \\
\text { indomethacin }\end{array}$ & $1-25 \mathrm{~h}$ & & $\begin{array}{l}\text { (Taepaiboon } \\
\text { et al., 2006) }\end{array}$ \\
\hline $\begin{array}{l}\text { Thảm sợi } \\
\text { nano điện tử }\end{array}$ & PVA & $\begin{array}{l}\text { Sodium } \\
\text { salicylate, } \\
\text { diclofenac, } \\
\text { naproxen, } \\
\text { indomethacin }\end{array}$ & Biến thiên & & $\begin{array}{l}\text { (Basar et al., } \\
\text { 2017) }\end{array}$ \\
\hline
\end{tabular}

PAA: Peracetic acid, PLGA: poly(lactic-co-glycolic acid), PVA: Polyvinyl alcohol, TSP: Trisodium phosphate, PLL: Poly-L-Lysin, PEG: polyethylene glycol, PPF: propofol, PDC: Polymer-Derived Ceramic, Poly(mPEGMA-co-MAA): đồng polymer của methoxy poly(ethylene glycol) methacrylate-co-poly(methacrylic acid), PCL: Poly(caprolactone), Electrospun: sợi tù̀ polymer dung dịch hoặc polymer nóng chảy bằng cách sủ dụng lục tĩnh điện (điện trương), PLG: Poly(D,L-lactide-co-glycolide), PLCA: Poly(caprolactone-co-lactic acid), PLGA: Poly(lactic-co-glycolic acid), PP: Polypropylene, PVA: Polyvinyl alcohol, PHB: Polyhydroxybutyrate, PLA: Polylactic acid, HA: hyaluronic acid, TPU: Polyurethan nhiệt dẻo.

Bảng 2. Hệ phân phối thuốc mới cho NSAID trong cải thiện điều trị viêm xương khớp

\begin{tabular}{|c|c|c|c|c|c|}
\hline Thuốc & $\begin{array}{l}\text { Lớp và } \\
\text { phân lớp } \\
\text { hóa học }\end{array}$ & $\begin{array}{l}\text { Hệ phân phối } \\
\text { thuốc }\end{array}$ & Thành phần & Quan sát & $\begin{array}{l}\text { Tài liệu tham } \\
\text { khảo }\end{array}$ \\
\hline \multirow{3}{*}{ Aspirin } & \multirow{3}{*}{$\begin{array}{l}\text { Lớp: } \\
\text { carboxylic } \\
\text { acid } \\
\text { Phân lớp: } \\
\text { salicylic } \\
\text { acid }\end{array}$} & Vi cầu micro & Polycarbonate & $\begin{array}{l}\text { Tải thuốc cao, tăng kích thước } \\
\text { hạt và tốc độ giải phóng thuốc }\end{array}$ & $\begin{array}{l}\text { (Thanoo et al., } \\
\text { 1993) }\end{array}$ \\
\hline & & Nano albumin & $\begin{array}{l}\text { Albumin huyết thanh } \\
\text { bò }\end{array}$ & $\begin{array}{l}\text { Phóng thích liên tục trong thời } \\
\text { gian dài }\end{array}$ & $\begin{array}{l}\text { (Das et al., } \\
\text { 2005) }\end{array}$ \\
\hline & & Phức hợp & Phospholipid đậu nành & $\begin{array}{l}\text { Cải thiện khả năng hòa tan và } \\
\text { sinh khả dụng }\end{array}$ & $\begin{array}{l}\text { (Semalty et al., } \\
2010 \text { ) }\end{array}$ \\
\hline \multirow{3}{*}{ Diclofenac } & \multirow{3}{*}{$\begin{array}{l}\text { Lớp: } \\
\text { carboxylic } \\
\text { acid } \\
\text { Phân lớp: } \\
\text { acetic acid }\end{array}$} & $\begin{array}{l}\text { Miếng dán thấm } \\
\text { qua da }\end{array}$ & $\begin{array}{l}\text { Teriflunomide, chất } \\
\text { kết dính nhạy cảm với } \\
\text { áp suất, chất bổ trợ } \\
\text { Freund, propylparaben }\end{array}$ & Thẩm thấu qua da tốt hơn & $\begin{array}{l}\text { (Zhang et al., } \\
\text { 2014) }\end{array}$ \\
\hline & & Liposome & Polyethylene glycol & Tăng cường phân phối qua da & $\begin{array}{l}\text { (Vyas et al., } \\
\text { 1995) }\end{array}$ \\
\hline & & Viên & Phim poly-methacrylic & Giải phóng đa hạt liên tục & $\begin{array}{l}\text { (Kramar et al., } \\
\text { 2003) }\end{array}$ \\
\hline
\end{tabular}




\begin{tabular}{|c|c|c|c|c|c|}
\hline Thuốc & $\begin{array}{l}\text { Lớp và } \\
\text { phân lớp } \\
\text { hóa học } \\
\end{array}$ & $\begin{array}{l}\text { Hệ phân phối } \\
\text { thuốc }\end{array}$ & Thành phần & Quan sát & $\begin{array}{l}\text { Tài liệu tham } \\
\text { khảo }\end{array}$ \\
\hline & & Vi nang micro & $\begin{array}{l}\text { Cellulose acetate } \\
\text { phthalate, } \\
\text { ethylcellulose }\end{array}$ & $\begin{array}{l}\text { Giải phóng thuốc ốn định và } \\
\text { đồng đều, cải thiện hoạt tính } \\
\text { kháng viêm }\end{array}$ & $\begin{array}{l}\text { (Biju et al., } \\
\text { 2004) }\end{array}$ \\
\hline & & Vi cầu micro & $\begin{array}{l}\text { Polymer phân hủy sinh } \\
\text { học tự nhiên }\end{array}$ & $\begin{array}{l}\text { Hoạt tính nhanh và kéo dài, } \\
\text { hiệu quả hướng mục tiêu tốt }\end{array}$ & $\begin{array}{l}\text { (Tuncay et al., } \\
\text { 2000) }\end{array}$ \\
\hline & & Nano-composite & Ethyl cellulose & $\begin{array}{l}\text { Dung nạp thuốc cao, giải } \\
\text { phóng thuốc kéo dài }\end{array}$ & $\begin{array}{l}\text { (Arias et al., } \\
\text { 2009) }\end{array}$ \\
\hline & & Gel niosome & Span 60, cholesterol & Tăng cường thẩm thấu qua da & $\begin{array}{l}\text { (Akbari et al., } \\
\text { 2021) }\end{array}$ \\
\hline & & Hydrogel & $\begin{array}{l}\text { Chitosan polyethylene } \\
\text { glycol hóa }\end{array}$ & Kiểm soát phóng thích thuốc & $\begin{array}{l}\text { (Ailincai et al., } \\
\text { 2021) }\end{array}$ \\
\hline \multirow{4}{*}{ Indomethacin } & \multirow{4}{*}{$\begin{array}{l}\text { Lớp: } \\
\text { carboxylic } \\
\text { acid } \\
\text { Phân lớp: } \\
\text { acetic acid }\end{array}$} & $\begin{array}{l}\text { Phim cellulose } \\
\text { acetate }\end{array}$ & Cellulose acetate & & $\begin{array}{l}\text { (Çetin et al., } \\
2004)\end{array}$ \\
\hline & & Vi nang nano & $\begin{array}{l}\text { Poly( } \varepsilon \text {-caprolactone), } \\
\text { capric/caprylic } \\
\text { triglyceride, sorbitan } \\
\text { monostearate }\end{array}$ & $\begin{array}{l}\text { Hoạt động kháng viêm tốt hơn, } \\
\text { cải thiện an toàn đường uống }\end{array}$ & $\begin{array}{l}\text { (Bernardi et } \\
\text { al., 2009) }\end{array}$ \\
\hline & & Liposome & $\begin{array}{l}\text { Proliposome dựa trên } \\
\text { hạt sủi bọt khô }\end{array}$ & Cải thiện hoạt tính kháng viêm & $\begin{array}{l}\text { (Katare et al., } \\
\text { 1995) }\end{array}$ \\
\hline & & $\begin{array}{l}\text { Bong bóng } \\
\text { micro nổi }\end{array}$ & $\begin{array}{l}\text { Eudragit RS100, } \\
\text { Eudragit S100 }\end{array}$ & $\begin{array}{l}\text { Khả năng nồi tốt, hoạt tính kéo } \\
\text { dài và được kiểm soát }\end{array}$ & $\begin{array}{l}\text { (Bhardwaj et } \\
\text { al., 2010) }\end{array}$ \\
\hline \multirow{10}{*}{ Ketoprofen } & \multirow{10}{*}{$\begin{array}{l}\text { Lớp: } \\
\text { carboxylic } \\
\text { acid } \\
\text { Phân lớp: } \\
\text { propionic } \\
\text { acid }\end{array}$} & Viên nén & $\begin{array}{l}\text { Gelatin, glycin, } \\
\text { sorbitol }\end{array}$ & $\begin{array}{l}\text { Tăng khả năng hòa tan và tốc } \\
\text { độ hòa tan }\end{array}$ & $\begin{array}{l}\text { (Ahmed et al., } \\
\text { 2006) }\end{array}$ \\
\hline & & Thuốc đạn & $\begin{array}{l}\text { Polyethylene glycol } \\
1000\end{array}$ & Hấp thụ thuốc tối ưu & $\begin{array}{l}\text { (Babar et al., } \\
\text { 1999) }\end{array}$ \\
\hline & & Vi nang micro & $\begin{array}{l}\text { Eudragit L100, } \\
\text { Eudragit S100, stearic } \\
\text { acid }\end{array}$ & Tải thuốc cao & $\begin{array}{l}\text { (Luppi et al., } \\
\text { 2009) }\end{array}$ \\
\hline & & Nhũ tương nano & $\begin{array}{l}\text { Ethanol, solutol, } \\
\text { benzyl alcohol }\end{array}$ & Mức độ ổn định cao & $\begin{array}{l}\text { (Kim et al., } \\
\text { 2008) }\end{array}$ \\
\hline & & $\begin{array}{l}\text { Hỗn hợp } \\
\text { lecithin - đậu } \\
\text { nành }\end{array}$ & Lecithin - đậu nành & Cải thiện độ thẩm thấu qua da & $\begin{array}{l}\text { (Valenta et al., } \\
\text { 2000) }\end{array}$ \\
\hline & & $\begin{array}{l}\text { Hệ thống phân } \\
\text { phối nổi - } \\
\text { đường uống }\end{array}$ & $\begin{array}{l}\text { Eudragit S100, } \\
\text { Eudragit RL }\end{array}$ & $\begin{array}{l}\text { Tăng thời gian lưu trữ trong dạ } \\
\text { dày }\end{array}$ & $\begin{array}{l}\text { (El-Kamel et } \\
\text { al., 2001) }\end{array}$ \\
\hline & & Pharmacosome & Phosphatidylcholine & Cải thiện độ hòa tan & $\begin{array}{l}\text { (Kavitha et al., } \\
\text { 2010) }\end{array}$ \\
\hline & & Vi cầu micro & & Tăng $C_{\max }, \mathrm{AUC}, \mathrm{t}_{1 / 2}$ & $\begin{array}{l}\text { (Mathew et al., } \\
\text { 2009) }\end{array}$ \\
\hline & & Viên matrix & $\begin{array}{l}\text { Ketoprofen tinh thể } \\
\text { nano }\end{array}$ & $\begin{array}{l}\mathrm{C}_{\max } \text { cao hơn, } \mathrm{t}_{\max } \text { thấp hơn, } \\
\text { phóng thích liên tục }\end{array}$ & $\begin{array}{l}\text { (Vergote et al., } \\
2002)\end{array}$ \\
\hline & & Liposome & $\begin{array}{l}\text { Chất hoạt động bề mặt } \\
\text { pyrrolidinium }\end{array}$ & Phóng thích cục bộ kéo dài & $\begin{array}{l}\text { (Kuznetsova et } \\
\text { al., 2021) }\end{array}$ \\
\hline \multirow{3}{*}{ Ibuprofen } & \multirow{3}{*}{$\begin{array}{l}\text { Lớp: } \\
\text { carboxylic } \\
\text { acid } \\
\text { Phân lớp: } \\
\text { propionic } \\
\text { acid }\end{array}$} & Vi cầu micro & $\begin{array}{l}\text { Ceresin, glyceryl } \\
\text { stearate }\end{array}$ & Phóng thích liên tục & $\begin{array}{l}\text { (Janjikhel \& } \\
\text { Adeyeye, } \\
\text { 1997) }\end{array}$ \\
\hline & & $\begin{array}{l}\text { Hydrogel trên } \\
\text { nhũ tương } \\
\text { micro }\end{array}$ & $\begin{array}{l}\text { Ethyl oleate, } \\
\text { propylene glycol, } \\
\text { xanthan gum, Tween } \\
80\end{array}$ & Độ bền cao & $\begin{array}{l}\text { (Chen et al., } \\
\text { 2006) }\end{array}$ \\
\hline & & Hạt alginate & $\begin{array}{l}\text { Sodium } \\
\text { carboxymethyl } \\
\text { cellulose, alginate }\end{array}$ & Ngăn ngừa tổn thương dạ dày & $\begin{array}{l}\text { (Arica et al., } \\
2005 \text { ) }\end{array}$ \\
\hline
\end{tabular}




\begin{tabular}{|c|c|c|c|c|c|}
\hline Thuốc & $\begin{array}{l}\text { Lớp và } \\
\text { phân lớp } \\
\text { hóa học }\end{array}$ & $\begin{array}{l}\text { Hệ phân phối } \\
\text { thuốc }\end{array}$ & Thành phần & Quan sát & $\begin{array}{l}\text { Tài liệu tham } \\
\text { khảo }\end{array}$ \\
\hline & & $\begin{array}{l}\text { Viên nhỏ hỗn } \\
\text { hợp }\end{array}$ & $\begin{array}{l}\text { Paracera M, DDWM, } \\
\text { triacetin }\end{array}$ & $\mathrm{C}_{\max }$ cao hơn & $\begin{array}{l}\text { (De et al., } \\
2000)\end{array}$ \\
\hline \multirow[b]{3}{*}{ Naproxen } & \multirow{3}{*}{$\begin{array}{l}\text { Lớp: } \\
\text { carboxylic } \\
\text { acid } \\
\text { Phân lớp: } \\
\text { propionic } \\
\text { acid }\end{array}$} & Viên hỗn hợp & $\begin{array}{l}\text { Methocel®K4M CR, } \\
\text { Methocel®K15 M CR }\end{array}$ & $\begin{array}{l}\text { Phóng thích thuốc theo cơ chế } \\
\text { khuếch tán }\end{array}$ & $\begin{array}{l}\text { (Islam et al., } \\
2010 \text { ) }\end{array}$ \\
\hline & & Hạt nano & $\begin{array}{l}\text { Hạt nano poly- } \\
\text { caprolactone }\end{array}$ & Hoạt tính kháng viêm kéo dài & $\begin{array}{l}\text { (Rodrigues et } \\
\text { al., 2011) }\end{array}$ \\
\hline & & Viên bao & $\begin{array}{l}\text { 2-Hydroxypropyl- } \beta \text { - } \\
\text { cyclodextrin, Eudragit } \\
\text { S100, Eudragit RS100, } \\
\text { dibutyl subacate, } \\
\text { aluminium tristearate }\end{array}$ & Giảm tổn thương mô ruột & $\begin{array}{l}\text { (Piao et al., } \\
\text { 2008) }\end{array}$ \\
\hline \multirow{4}{*}{ Celecoxib } & \multirow{4}{*}{$\begin{array}{l}\text { Lớp: chọn } \\
\text { lọc COX-2 } \\
\text { Phân lớp: } \\
\text { sulfonamide }\end{array}$} & Vi cầu micro & $\begin{array}{l}\text { Albumin huyết thanh } \\
\text { bò }\end{array}$ & $\begin{array}{l}\text { Phóng thích thuốc liên tục, thời } \\
\text { gian tác dụng kéo dài }\end{array}$ & $\begin{array}{l}\text { (Thakkar et al., } \\
\text { 2005) }\end{array}$ \\
\hline & & $\begin{array}{l}\text { Vi cầu micro } \\
\text { chitosan }\end{array}$ & Chitosan & $\begin{array}{l}\text { Phân phối nhanh, tăng nồng độ } \\
\text { thuốc trong khớp }\end{array}$ & $\begin{array}{l}\text { (Thakkar et al., } \\
\text { 2004) }\end{array}$ \\
\hline & & Vi nhũ tương & $\begin{array}{l}\text { Polyethylene glycol, } \\
\text { caprylic/ capric } \\
\text { glyceride, Tween } 20, \\
\text { propylene glycol } \\
\text { monocaprylic ester }\end{array}$ & $\begin{array}{l}\text { Giảm thiểu sự thay đổi trong } \\
\text { hấp thu, khởi phát tác dụng } \\
\text { nhanh }\end{array}$ & $\begin{array}{l}\text { (Subramanian } \\
\text { et al., 2004) }\end{array}$ \\
\hline & & Micelle nano & $\begin{array}{l}\text { Pluronic P123: sodium } \\
\text { taurocholate }(1: 1)\end{array}$ & $\begin{array}{l}\text { Hướng mục tiêu đại tràng, điều } \\
\text { trị viêm ruột }\end{array}$ & $\begin{array}{l}\text { (El-Hady et al., } \\
\text { 2020) }\end{array}$ \\
\hline \multirow{5}{*}{ Meloxicam } & \multirow{5}{*}{$\begin{array}{l}\text { Lớp: enolic } \\
\text { acid } \\
\text { Phân lớp: } \\
\text { Oxicam }\end{array}$} & $\begin{array}{l}\text { Phim cellulose } \\
\text { acetate }\end{array}$ & Cellulose acetate & Phóng thích cục bộ kéo dài & $\begin{array}{l}\text { (Çetin et al., } \\
\text { 2004) }\end{array}$ \\
\hline & & $\begin{array}{l}\text { Đa hạt nổi - linh } \\
\text { động }\end{array}$ & $\begin{array}{l}\text { Calcium silicate, } \\
\text { sodium alginate }\end{array}$ & $\begin{array}{l}\text { Phóng thích thuốc theo chương } \\
\text { trình }\end{array}$ & $\begin{array}{l}\text { (Sharma \& } \\
\text { Pawar, 2006) }\end{array}$ \\
\hline & & $\begin{array}{l}\text { Thẩm thấu qua } \\
\text { da }\end{array}$ & $\begin{array}{l}\text { Isopropyl myristate, } \\
\text { Tween } 85 \text {, ethanol }\end{array}$ & Hấp thu qua da cao & $\begin{array}{l}\text { (Yuan et al., } \\
\text { 2006) }\end{array}$ \\
\hline & & $\begin{array}{l}\text { Viên nén phân } \\
\text { tán }\end{array}$ & $\begin{array}{l}\text { Tinh bột sodium } \\
\text { glycolate, aerosil, } \\
\text { sodium } \\
\text { croscarmellose, } \\
\text { Pearlitol SD200, } \\
\text { cellulose vi tinh thể }\end{array}$ & $\begin{array}{l}\text { Đặc tính phóng thích thuốc tốt } \\
\text { hơn }\end{array}$ & $\begin{array}{l}\text { (Swamy et al., } \\
\text { 2007) }\end{array}$ \\
\hline & & Liposome & $\begin{array}{l}\text { Chất hoạt động bề mặt } \\
\text { pyrrolidinium }\end{array}$ & Phóng thích cục bộ kéo dài & $\begin{array}{l}\text { (Kuznetsova et } \\
\text { al., 2021) }\end{array}$ \\
\hline \multirow{8}{*}{ Piroxicam } & \multirow{8}{*}{$\begin{array}{l}\text { Lớp: enolic } \\
\text { acid } \\
\text { Phân lớp: } \\
\text { Oxicam }\end{array}$} & $\begin{array}{l}\text { Vi cầu micro } \\
\text { nổi }\end{array}$ & Eudragit S100 & $\begin{array}{l}\text { Phóng thích thuốc nhanh hơn ở } \\
\text { pH ruột }\end{array}$ & $\begin{array}{l}\text { (Kale \& } \\
\text { Tayade, 2007) }\end{array}$ \\
\hline & & $\begin{array}{l}\text { Viên nang } \\
\text { gelatin cứng }\end{array}$ & $\begin{array}{l}\text { Gelucire 44/14, } \\
\text { labrasol }\end{array}$ & Khởi đầu tác dụng nhanh & $\begin{array}{l}\text { (Yüksel et al., } \\
\text { 2003) }\end{array}$ \\
\hline & & $\begin{array}{l}\text { Gel thẩm thấu } \\
\text { qua da với chất } \\
\text { kết dính } \\
\text { Proniosome }\end{array}$ & Lecithin maltodextrin & Tăng cường thẩm thấu & $\begin{array}{l}\text { (Sharma, } \\
\text { 2008) }\end{array}$ \\
\hline & & $\begin{array}{l}\text { Vi cầu micro } \\
\text { rỗng, nổi }\end{array}$ & $\begin{array}{l}\beta \text {-Cyclodextrin, } \\
\text { carboxyvinylic gel }\end{array}$ & $\begin{array}{l}\text { Kéo dài thời gian tác dụng, } \\
\text { tăng sinh khả dụng }\end{array}$ & $\begin{array}{l}\text { (Joseph et al., } \\
\text { 2002) }\end{array}$ \\
\hline & & $\begin{array}{l}\text { Phức kết hợp vi } \\
\text { nhũ tương }\end{array}$ & & Tác dụng kháng viêm kéo dài & $\begin{array}{l}\text { (Dalmora et } \\
\text { al., 2001) }\end{array}$ \\
\hline & & $\begin{array}{l}\text { Vi nhũ tương } \\
\text { dầu - nước }\end{array}$ & $\begin{array}{l}\text { Oleic acid, labrasol, } \\
\text { ethanol }\end{array}$ & Cải thiện thẩm thấu qua da & $\begin{array}{l}\text { (Park et al., } \\
2005)\end{array}$ \\
\hline & & Hạt nano & Poly- $\varepsilon$-caprolactone & Tác dụng kháng viêm kéo dài & $\begin{array}{l}\text { (Rahmani Del } \\
\text { Bakhshayesh } \\
\text { et al., 2020) }\end{array}$ \\
\hline & & Hạt nano & Phospholipon ${ }^{\circledR} 90 \mathrm{H}$ & Tăng cường thẩm thấu qua da & $\begin{array}{l}\text { (Mbah et al., } \\
\text { 2021) }\end{array}$ \\
\hline
\end{tabular}




\subsection{Tiêm tại chỗ}

Hệ thống phóng thích có thể giải phóng thuốc trong khu vực cục bộ, do đó loại bỏ hoàn toàn tác dụng phụ ngoài mục tiêu và chỉ cần liều lượng nhỏ để đạt được nồng độ trị liệu. Phương tiện phóng thích cục bộ không cần phải đi qua hệ tuần hoàn, thay vào đó chỉ tác động tại khu vực được viêm. Các vector phân phối cục bộ có lợi thế gấp đôi khi chúng không yêu cầu bất kỳ phẫu thuật nào để cấy ghép. Trong trường hợp hệ thống phóng thích đủ nhỏ và có độ nhớt đủ thấp để đi qua được kim thì đưa vào cơ thể rất dễ dàng (Bảng 1). Các hệ thống điển hình có đặc tính mong muốn này thường là hạt nano hoặc hệ liên hợp thuốc (Fattahpour et al., 2015; Sulistio et al., 2017; Wang et al., 2007).

Mặc dù phóng thích kéo dài là không cần thiết cho kiểu phóng thích này nhưng đó là một lợi thế vì viêm xương khớp là trọng tâm nghiên cứu chính cho loại hệ thống này (Fattahpour et al., 2015; Thing et al., 2014). Tiêm vào các khớp bị ảnh hưởng chẳng hạn như đầu gối có thể thực hiện theo yêu cầu nhưng số lần tiêm ít hơn được ưu tiên và đảm bảo cho sự tuân thủ điều trị. Ở loại phóng thích này, hai nghiên cứu cho thấy hệ phân phối thuốc có thời gian phóng thích kéo dài và hiệu quả điều trị cao. Hệ phân phối thuốc diclofenac-PEG (polyethylene glycol) được điều chế bởi Sulistio et al. (2017) cho thấy sự phóng thích thuốc trong hơn 100 ngày ở thử nghiệm sơ bộ in vitro và một loại polymer nhớt chứa ketoprofen cho thấy sự phóng thích trong khoảng ba tháng trong điều kiện in vitro tương tự. Trong những trường hợp này, bệnh nhân chỉ cần tiêm bốn đến năm lần một năm để điều trị hiệu quả giảm đau và tăng chất lượng cuộc sống (Sulistio et al., 2017; Wang et al., 2007).

\subsection{Phóng thích cục bộ}

Phóng thích cục bộ là một trong những loại lớn nhất được trình bày trong đánh giá này do định nghĩa tổng quát và có nhiều hệ thống phóng thích khác nhau được áp dụng. Tiêm cục bộ về mặt kỹ thuật là một loại nhỏ của phóng thích cục bộ và hệ thống phóng thích được liệt kê ở đây có khả năng tiêm bằng kim thấp hơn (Amrite et al., 2006; Park et al., 2016). Tuy nhiên, những phương tiện được chế tạo đặc biệt để tiêm được loại bỏ khỏi thể loại phóng thích cục bộ trong đánh giá này. Hydrogel, hạt micro (microparticle), vi cầu (microsphere), phim/ màng và sợi (fiber) là tất cả các loại phương tiện có thể được sử dụng để vận chuyển thuốc cục bộ (Bảng 1). Các loại phương tiện này yêu cầu phẫu thuật để cấy ghép nếu kích thước quá lớn để tiêm, trừ khi chúng được sử dụng trong các ứng dụng nha khoa - nơi niêm mạc cho phép thuốc xâm nhập ở bề mặt. PLGA (poly(lactic-co-glycolic acid)) và chitosan là vật liệu phổ biến cho loại phóng thích này do khả năng phân hủy sinh học và loại bỏ sau khi phân bố thuốc đã kết thúc (Canbolat et al., 2014; Yar et al., 2016). Dường như không có một ưu tiên rõ ràng nào để cung cấp một NSAID cụ thể so với các loại thuốc khác, đã có nhiều kết hợp NSAID và các loại vật liệu/ phương tiện đã được nghiên cứu.

Bệnh nha khoa - viêm mô xung quanh răng là một trường hợp cần ứng dụng phóng thích cục bộ do khả năng tiếp cận khu vực viêm. Sợi (fiber) hoặc thảm (mat) mang thuốc có thể được đặt với độ chính xác cao vào vị trí cần thiết và dễ dàng tăng nồng độ thuốc tại vị trí viêm. Các trường hợp cung cấp NSAID cục bộ được khuyến cáo là điều trị bệnh võng mạc đái tháo đường và hàng rào chống dính mô được sử dụng trong nhiều quy trình phẫu thuật. Trong những trường hợp này, tình trạng viêm được tập trung hóa cao tại một địa điểm, do đó cho phép phóng thích cục bộ để cải thiện tất cả các triệu chứng mà không ảnh hưởng đến các khu vực ngoài mục tiêu (Liu et al., 2017).

\subsection{Lớp phủ hoặc kết hợp cấy ghép}

Viêm là phản ứng tự nhiên của cơ thể đối với chấn thương và nhiễm trùng nhưng cấy ghép y sinh là nguyên nhân rất phổ biển của triệu chứng viêm không mong muốn. Khi tình trạng viêm ảnh hưởng lâu dài đến cơ thể tại vị trí cấy ghép thì có thể gây sốt và đau hoặc thậm chí cần phải loại bỏ mô cấy (Horvat et al., 2017; Sidney et al., 2015). Do đó, việc thêm thành phần phân phối thuốc vào bộ phận cấy ghép là một bước dễ dàng của chiến lược phân phối thuốc mới góp phần giảm tác dụng phụ (Bảng 1).

Hệ phân phối thuốc này sẽ phóng thích cục bộ và tương tác chủ yếu với bộ phận cấy ghép (lớp phủ hoặc vật liệu cấy ghép). Ngoài ra, hệ phân phối còn có thời gian phóng thích kéo dài vì phần lớn mô cấy bằng vật liệu sinh học đều ở trong cơ thể lâu dài và thường không thể bổ sung thuốc mới. Giảm viêm trong thời gian ngắn sẽ có lợi trong chữa lành vết thương nhưng giảm viêm trong thời gian dài sẽ giữ cho cơ thể không phản ứng liên tục với mô cấy. Hơn nữa, tình trạng viêm có thể cản trở chữa lành và tái tạo xương, phóng thích kéo dài là rất quan trọng đối với một số loại cấy ghép thông thường như thay toàn bộ khớp háng hoặc đầu gối. Sự thành công của phóng thích kéo dài cho thấy rằng đây là loại phương tiện tiềm năng và cần được quan tâm nghiên cứu trong tương lai với các NSAID có thời gian bán hủy dài hơn diclofenac (Goimil et al., 2017; Jia \& Kerr, 2013). 


\subsection{Phân phối thuốc qua da}

Việc sử dụng thuốc qua da về mặt khái niệm rất đơn giản nhưng thực tế rất khó khăn. Có rất ít loại thuốc phù hợp với phương pháp phân phối qua da một cách tự nhiên, vì khối lượng phân tử, tính ưa nước, thời gian bán hủy và liều lượng là tất cả các yếu tố phá vỡ quá trình phân phối tại chỗ thành công (Ahad et al., 2014). Tuy nhiên, phân phối tại chỗ là một lựa chọn hấp dẫn, dễ sử dụng và bệnh nhân tuân thủ cao (Bảng 1). Ngoài ra, một khi thuốc vượt qua được lớp sừng - hàng rào bên ngoài của da cản trở việc phân phối thì thuốc có thể đạt nồng độ cao tại chỗ. Đây là một mục tiêu hấp dẫn cho cả việc chữa lành vết thương và điều trị viêm xương khớp (Amodwala et al., 2017).

Meloxicam là một trong số ít NSAID được chứng minh là một thuốc đầy hứa hẹn cho phương pháp này, chủ yếu là do tính thẩm thấu cao và độ hòa tan thấp. Hầu hết các NSAID có độ hòa tan thấp, nhưng khả năng thẩm thấu lại là một vấn đề khác. Ví dụ, naproxen, mặc dù đã được sử dụng trong một số thử nghiệm phân phối tại chỗ nhưng sinh khả dụng kém khi hấp thụ qua da. Ngược lại, có những vector phân phối thành công như miếng dán và gel giải phóng meloxicam đạt được nồng độ mong muốn. Các công thức này đã được chứng minh là có thể điều trị cả ngày trong in vitro. Do gel và miếng dán dễ sử dụng, việc dùng thuốc hàng ngày có thể chấp nhận để kiểm soát các tình trạng như viêm xương khớp (Ah et al., 2010; Akbari et al., 2016). Nhiều nghiên cứu vẫn đang tiếp tục nhằm tối ưu hóa hệ phân phối thuốc NSAID trong điều trị viêm xương khớp cũng như viêm khớp dạng thấp (Bảng 2).

\section{KẾT LUẬN}

Có rất nhiều nghiên cứu đã và đang được thực hiện để khám phá phương tiện hoặc hệ thống tiềm năng phân phối thuốc cho NSAID như một phương pháp thay thế cho việc phân phối toàn thân. Cung cấp thuốc toàn thân đã được chứng minh là gây ra tác dụng phụ nghiêm trọng và việc giảm thiểu các tác dụng phụ này là rất cần thiết do thuốc chống viêm có ứng dụng và sử dụng rộng rãi. Mặc dù nhiều nghiên cứu trong số này vẫn đang trong giai đoạn phát triển ban đầu nhưng có đủ dữ liệu để kết luận rằng toàn bộ lĩnh vực có thể được cải thiện bằng lựa chọn thông minh hơn về cả hai loại: vector phân phối và NSAID. Những lựa chọn này sẽ phụ thuộc rất nhiều vào ứng dụng phân phối. Phân phối qua da yêu cầu các thuộc tính rất cụ thể để hoạt động chính xác. Những trường hợp khác như phân phối cục bộ ít yêu cầu điều kiện hơn. Đã có những thành công trong lĩnh vực này nhưng cũng có những thất bại có thể tránh được do thiếu tiêu chuẩn hóa và dữ liệu công khai. Khi lĩnh vực tiếp tục mở rộng, các tài liệu đánh giá như nghiên cứu này sẽ trở nên quan trọng để hỗ trợ thiết kế thử nghiệm trong tương lai, đặc biệt cho phép các nhà nghiên cứu xác định thuốc và phương tiện phân phối có lợi nhất để theo đuổi và cuối cùng để xác định hệ phân phối NSAID tối ưu cho sử dụng lâm sàng.

\section{TÀI LIÊU THAM KHẢO}

Ah, Y. C., Choi, J. K., Choi, Y. K., Ki, H. M. \& Bae, J. H. (2010). A novel transdermal patch incorporating meloxicam: in vitro and in vivo characterization. International Journal of Pharmaceutics, 385(1-2), 12-19. DOI: 10.1016/j.ijpharm.2009.10.013

Ahad, A., Raish, M., Al-Mohizea, A. M., AlJenoobi, F. I. \& Alam, M. A. (2014). Enhanced anti-inflammatory activity of carbopol loaded meloxicam nanoethosomes gel. International Journal of Biological Macromolecules, 67, 99104. DOI: 10.1016/j.ijbiomac.2014.03.011

Ahmed, I., Nafadi, M. \& Fatahalla, F. (2006). Formulation of a fast-dissolving ketoprofen tablet using freeze-drying in blisters technique. Drug Development and Industrial Pharmacy, 32(4), 437-442. DOI: 10.1080/03639040500528913

Ailincai, D., Agop, M., Marinas, I. C., Zala, A., Irimiciuc, S. A., Dobreci, L., Petrescu, T. C., Volovat, C. (2021). Theoretical model for the diclofenac release from PEGylated chitosan hydrogels. Drug Delivery, 28(1), 261-271. DOI: 10.1080/10717544.2021.1876181

Akbari, J., Saeedi, M., Morteza-Semnani, K., Hashemi, S. M. H., Babaei, A., Eghbali, M., Mohammadi, M., Rostamkalaei, S. S., AsareAddo, K., Nokhodchi, A. (2021). Innovative topical niosomal gel formulation containing diclofenac sodium (niofenac). Journal of Drug Targeting, 1-10. DOI: 10.1080/1061186X.2021.1941060.

Akbari, J., Saeedi, M., Morteza-Semnani, K., Rostamkalaei, S. S., Asadi, M., Asare-Addo, K. $\&$ Nokhodchi, A. (2016). The design of naproxen solid lipid nanoparticles to target skin layers. Colloids Surf B Biointerf, 145, 626-633. DOI: 10.1016/j.colsurfb.2016.05.064

Akduman, C., Ozgueney, I. \& Kumbasar, E. P. A. (2014). Electrospun thermoplastic polyurethane mats containing naproxen-cyclodextrin inclusion complex. Autex Research Journal, 14(4), 239246. DOI: 10.2478 /aut-2014-0024

Akduman, C., Ozgueney, I. \& Kumbasar, E. P. A. (2016). Preparation and characterization of 
naproxen-loaded electrospun thermoplastic polyurethane nanofibers as a drug delivery system. Materials Science and Engineering $C$ : Materials for Biological Applications, 64, 383390. DOI: 10.1016/j.msec.2016.04.005

Amodwala, S., Kumar, P. \& Thakkar, H. P. (2017). Statistically optimized fast dissolving microneedle transdermal patch of meloxicam: a patient friendly approach to manage arthritis. European Journal of Pharmaceutical Sciences, 104, 114-123. DOI: 10.1016/j.ejps.2017.04.001

Amrite, A. C., Ayalasomayajula, S. P., Cheruvu, N. P. S. \& Kompella, U. B. (2006). Single periocular injection of celecoxib-PLGA microparticles inhibits diabetesinduced elevations in retinal PGE2, VEGF, and vascular leakage. Investigative Ophthalmology \& Visual Science, 47(3), 1149-1160. DOI:

10.1167/iovs.05-0531

Arias, J. L., López-Viota, M., López-Viota, J. \& Delgado, Á. V. (2009). Development of iron/ ethylcellulose (core/shell) nanoparticles loaded with diclofenac sodium for arthritis treatment. International Journal of Pharmaceutics, 382(12), 270-276. DOI:

10.1016/j.ijpharm.2009.08.019

Arica, B., Çaliş, S., Atilla, P., Durlu, N., Cakar, N., Kaş, H. \& Hincal, A. (2005). In vitro and in vivo studies of ibuprofen-loaded biodegradable alginate beads. Journal of Microencapsulation, 22(2), 153-165. DOI: $10.1080 / 02652040400026319$

Babar, A., Bellete, T. \& Plakogiannis, F. (1999). Ketoprofen suppository dosage forms: in vitro release and in vivo absorption studies in rabbits. Drug Development and Industrial Pharmacy, 25(2), 241-245. DOI: 10.1081/ddc-100102166

Badri, W., Miladi, K., Nazari, Q. A., Greige-Gerges, H., Fessi, H. \& Elaissari, A. (2016). Encapsulation of NSAIDs for inflammation management: overview, progress, challenges and prospects. International Journal of Pharmaceutics, 515(1-2), 757-773. DOI: 10.1016/j.ijpharm.2016.11.002

Baruch, L., Benny, O., Gilert, A., Ukobnik, M., Ben, I. O. \& Machluf, M. (2009). Alginate-PLL cell encapsulation system Co-entrapping PLGAmicrospheres for the continuous release of antiinflammatory drugs. Biomedical Microdevices, 11(5), 1103-1113. DOI: 10.1007/s10544-0099327-3

Basar, A. O., Castro, S., Torres-Giner, S., Lagaron, J. M. \& Sasmazel, H. T. (2017). Novel poly(ecaprolactone)/gelatin wound dressings prepared by emulsion electrospinning with controlled release capacity of Ketoprofen anti-inflammatory drug. Materials Science and Engineering C, 81, 459-468. DOI: 10.1016/j.msec.2017.08.025

Bernardi, A., Zilberstein, A., Jäger, E., Campos, M., Morrone, F., Calixto, J., Pohlmann, A., Guterres, S. \& Battastini, A. (2009). Effects of indomethacin-loaded nanocapsules in experimental models of inflammation in rats. British Journal of Pharmacology, 158(4), 11041111. DOI: 10.1111/j.1476-5381.2009.00244.X

Bhardwaj, P., Chaurasia, H., Chaurasia, D., Prajapati, S. K. \& Singh, S. (2010). Formulation and in-vitro evaluation of floating microballoons of indomethacin. Acta Poloniae Pharmaceutica, 67(3), 291-298.

Biju, S., Saisivam, S., Rajan, N. M. G. \& Mishra, P. (2004). Dual coated erodible microcapsules for modified release of diclofenac sodium. European Journal of Pharmaceutics and Biopharmaceutics, 58(1), 61-67. DOI: 10.1016/j.ejpb.2004.03.021

Boateng, J. S., Pawar, H. V. \& Tetteh, J. (2013). Polyox and carrageenan based composite film dressing containing anti-microbial and antiinflammatory drugs for effective wound healing. International Journal of Pharmaceutics, 441(12), 181-191. DOI: 10.1016/j.ijpharm.2012.11.045

Canbolat, M. F., Celebioglu, A. \& Uyar, T. (2014). Drug delivery system based on cyclodextrinnaproxen inclusion complex incorporated in electrospun polycaprolactone nanofibers. Colloids Surf B, 115, 15-21. DOI: 10.1016/j.colsurfb.2013.11.021

Çetin, E. Ö., Buduneli, N., Atlıhan, E. \& Kırılmaz, L. (2004). In vitro studies on controlled-release cellulose acetate films for local delivery of chlorhexidine, indomethacin, and meloxicam. Journal of Clinical Periodontology, 31(12), 1117-1121. DOI: 10.1111/j.1600051X.2004.00620.x

Chen, H., Chang, X., Du, D., Li, J., Xu, H. \& Yang, X. (2006). Microemulsion-based hydrogel formulation of ibuprofen for topical delivery. International Journal of Pharmaceutics, 315(1), 52-58. DOI: 10.1016/j.ijpharm.2006.02.015

Choi, J. M., Lee, B., Jeong, D., Park, K. H., Choi, E. J., Jeon, Y. J., Dindulkar, S. D., Cho, E., Do, S. H., Lee, K., Lee, I. S., Park, S., Jun, B. H., Yu, J. H. \& Jung, S. (2017). Characterization and regulated naproxen release of hydroxypropyl cyclosophoraose-pullulan microspheres. Journal of Industrial and Engineering Chemistry, 48, 108-118. DOI: 10.1016/j.jiec.2016.12.026

Dalmora, M., Dalmora, S. \& Oliveira, A. G. D. (2001). Inclusion complex of piroxicam with $\beta$ cyclodextrin and incorporation in cationic microemulsion. In vitro drug release and in vivo 
topical anti-inflammatory effect. International Journal of Pharmaceutics, 222(1), 45-55. DOI: 10.1016/s0378-5173(01)00692-5

Das, S. \& Subuddhi, U. (2016). Controlled and targeted delivery of diclofenac sodium to the intestine from $\mathrm{pH}$-Responsive chitosan/ poly(vinyl alcohol) interpenetrating polymeric network hydrogels. Polymer Science Series A, 58, 154-166. DOI: 10.1134/S0965545X16020048

Das, S., Banerjee, R. \& Bellare, J. (2005). Aspirin loaded albumin nanoparticles by coacervation: implications in drug delivery. Trends in Biomaterials and Artificial Organs, 18(2), 203-212.

De, C., Vervaet, C., Görtz, J., Remon, J. P. \& Berlo, J. (2000). Bioavailability of ibuprofen from matrix mini-tablets based on a mixture of starch and microcrystalline wax. International Journal of Pharmaceutics, 208(1), 81-86. DOI: 10.1016/s0378-5173(00)00549-4

Djekic, L., Martinovic, M., Stepanovic-Petrovic, R., Micov, A., Tomic, M. \& Primorac, M. (2016). Formulation of hydrogel-thickened nonionic microemulsions with enhanced percutaneous delivery of ibuprofen assessed in vivo in rats. European Journal of Pharmaceutical Sciences, 92, 255-265. DOI: 10.1016/j.ejps.2016.05.005

El-Hady, S. M., AbouGhaly, M. H. H., ElAshmoony, M. M., Helmy, H. S., El-Gazayerly, O. N. (2020). Colon targeting of celecoxib nanomixed micelles using pulsatile drug delivery systems for the prevention of inflammatory bowel disease. International Journal of Pharmaceutics, 576, 118982. DOI: 10.1016/j.ijpharm.2019.118982

El-Kamel, A., Sokar, M., Al Gamal, S. \& Naggar, V. (2001). Preparation and evaluation of ketoprofen floating oral delivery system. International Journal of Pharmaceutics, 220(1), 13-21. DOI: 10.1016/s0378-5173(01)00574-9

Farooq, A., Yar, M., Khan, A. S., Shahzadi, L., Siddiqi, S. A., Mahmood, N., Rauf, A., Qureshi, Z.U. A., Manzoor, F., Chaudhry, A. A. \& Ur Rehman, I. (2015). Synthesis of piroxicam loaded novel electrospun biodegradable nanocomposite scaffolds for periodontal regeneration. Materials Science and Engineering C: Materials for Biological Applications, 56, 104-113. DOI: 10.1016/j.msec.2015.06.006

Fattahpour, S., Shamanian, M., Tavakoli, N., Fathi, M., Sheykhi, S. R. \& Fattahpour, S. (2015). Design and optimization of alginate - chitosan pluronic nanoparticles as a novel meloxicam drug delivery system. Journal of Applied Polymer Science, 132(28), 1-12. DOI: 10.1002/app.42241

Ghazaie, M., Ghiaci, P. \& Ghiaci, M. (2017). Study on release of naproxen and metformin encapsulated in biopolymer-inorganic mesoporous matrices as controlled drug-delivery systems. Microporous and Mesoporous Mater, 244, 291-300. DOI: 10.1016/j.micromeso.2016.11.004

Goimil, L., Braga, M. E. M., Dias, A. M. A., GomezAmoza, J. L., Concheiro, A., Alvarez-Lorenzo, C., de Sousa, H. C. \& Garcia-Gonza'lez, C. A. (2017). Supercritical processing of starch aerogels and aerogel-loaded poly(e-caprolactone) scaffolds for sustained release of ketoprofen for bone regeneration. Journal of $\mathrm{CO}_{2}$ Utilization, 18, 237-249. DOI: 10.1016/j.jcou.2017.01.028

Hawkey, C. J. (2001). COX-1 and COX-2 inhibitors. Best Practice \& Research Clinical Gastroenterology, 15(5), 801-820. DOI: 10.1053/bega.2001.0236

Horvat, G., Xhanari, K., Finsgar, M., Gradisnik, L., Maver, U., Knez, Z. \& Novak, Z. (2017). Novel ethanol-induced pectin-xanthan aerogel coatings for orthopedic applications. Carbohydrate Polymer, 166, 365-376. DOI: 10.1016/j.carbpol.2017.03.008

Hosseinzadeh, H. (2011). Controlled release of diclofenac sodium from $\mathrm{pH}$-responsive carrageenan-g-poly(acrylic acid) superabsorbent hydrogel. Journal of Chemical Sciences, 122(4), 651-659. DOI: 10.1007/s12039-010-0100-1

Islam, M. R., Ahmed, I., Quadir, M. A. \& Rahman, M. H. (2010). Once daily sustained-release matrix tablet of naproxen: formulation and in vitro evaluation. Dhaka University Journal of Pharmaceutical Sciences, 9(1), 47-52. DOI: 10.3329/dujps.v9i1.7429

Janjikhel, R. K. \& Adeyeye, C. M. (1997). Stereospecific formulation and characterization of sustained release ibuprofen microspheres. Journal of Microencapsulation, 14(4), 409-426. DOI: $10.3109 / 02652049709033826$

Jia, H. \& Kerr, L. L. (2013). Sustained ibuprofen release using composite poly(lacticco-glycolic acid)/titanium dioxide nanotubes from Ti implant surface. Journal of Pharmaceutical Sciences, 102(7), 2341-2348. DOI: 10.1002/jps. 23580

Joseph, N., Lakshmi, S. \& Jayakrishnan, A. (2002). A floating-type oral dosage form for piroxicam based on hollow polycarbonate microspheres: in vitro and in vivo evaluation in rabbits. Journal of Controlled Release, 79(1), 71-79. DOI: 10.1016/s0168-3659(01)00507-7

Kale, R. \& Tayade, P. (2007). A multiple unit floating drug delivery system of piroxicam using eudragit polymer. Indian Journal of Pharmaceutical Sciences, 69(1), 120-123. DOI: 10.4103/0250-474X.32124

Kamari, Y. \& Ghiaci, M. (2016). Preparation and characterization of ibuprofen/ modified 
chitosan/ $/ \mathrm{TiO}_{2}$ hybrid composite as a controlled drugdelivery system. Microporous Mesoporous Mater, 234, 361-369. DOI:

10.1016/j.micromeso.2016.07.030

Karami, Z., Sadighian, S., Rostamizadeh, K., Parsa, M. \& Rezaee, S. (2016). Naproxen conjugated $\mathrm{mPEG}-\mathrm{PCL}$ micelles for dual triggered drug delivery. Materials Science and Engineering $C$ : Materials for Biological Applications, 61, 665673. DOI: 10.1016/j.msec.2015.12.067

Katare, O., Vyasx, S. \& Dixit, V. (1995). Enhanced in vivo performance of liposomal indomethacin derived from effervescent granule based proliposomes. Journal of Microencapsulation, 12(5), 487-493. DOI: 10.3109/02652049509006779

Kavitha, D., Sowjanya, J. N. \& Panaganti, S. (2010). Pharmacosomes: an emerging vesicular system. International Journal of Pharmaceutical Sciences Review and Research, 5(3), 168-171.

Kenawy, E. R., Abdel-Hay, F. I., El-Newehy, M. H. \& Wnek, G. E. (2007). Controlled release of ketoprofen from electrospun poly(vinyl alcohol) nanofibers. Materials Science and Engineering, 459(1-2), 390-396. DOI:

10.1016/j.msea.2007.01.039

Kim, B. S., Won, M., Yang, Lee, K. M. \& Kim, C. S. (2008). In vitro permeation studies of nanoemulsions containing ketoprofen as a model drug. Drug Delivery, 15(7), 465-469. DOI: 10.1080/10717540802328599

Kramar, A., Turk, S. \& Vrecer, F. (2003). Statistical optimisation of diclofenac sustained release pellets coated with polymethacrylic films. International Journal of Pharmaceutics, 256(1), 43-52. DOI: 10.1016/s0378-5173(03)00061-9

Kumar, R., Singh, A., Garg, N. \& Siril, P. F. (2018). Solid lipid nanoparticles for the controlled delivery of poorly water soluble non-steroidal anti-inflammatory drugs. Ultrasonics Sonochemistry, 40(Pt A), 686-696. DOI: 10.1016/j.ultsonch.2017.08.018

Kurkuri, M. D. \& Aminabhavi, T. M. (2004). Poly(vinyl alcohol) and poly(acrylic acid sequential interpenetrating network $\mathrm{pH}$-sensitive microspheres for the delivery of diclofenac sodium to the intestine. Journal of Controlled Release, 96(1), 9-20. DOI: 10.1016/j.jconrel.2003.12.025

Kuznetsova, D. A., Vasileva, L. A., Gaynanova, G. A., Vasilieva, E. A., Lenina, O. A., Nizameev, I. R., Kadirov, M. K., Petrov, K. A., Zakharova, L. Y., Sinyashin, O. G. (2021). Cationic liposomes mediated transdermal delivery of meloxicam and ketoprofen: Optimization of the composition, in vitro and in vivo assessment of efficiency.
International Journal of Pharmaceutics, 605, 120803. DOI: 10.1016/j.ijpharm.2021.120803

Khanal, S., Adhikari, U., Rijal, N., Bhattarai, S., Sankar, J. \& Bhattarai, N. (2016). pH-

Responsive PLGA nanoparticle for controlled payload delivery of diclofenac sodium. Journal of Functional Biomaterials, 7(3), 21-26. DOI: 10.3390/jfb7030021

Lins, L. C., Padoin, N., Pires, A.T. N. \& Soares, C. (2015). Modeling ketoprofen release from $\mathrm{PHB} /$ chitosan composite microparticles. Polymer Bulletin, 73(6), 1515-1520. DOI: 10.1007/s00289-015-1559-1

Liu, S., Pan, G., Liu, G., Neves, J. D., Song, S., Chen, S., Cheng, B., Sun, Z., Sarmento, B., Cui, W. \& Fan, C. (2017). Electrospun fibrous membranes featuring sustained release of ibuprofen reduce adhesion and improve neurological function following lumbar laminectomy. Journal of Controlled Release, 264, 1-13. DOI: 10.1016/j.jconrel.2017.08.011

Luppi, B., Bigucci, F., Zecchi, V. \& Cerchiara, T. (2009). Gastroresistant microcapsules: new approaches for site-specific delivery of ketoprofen. Drug Delivery, 16(1), 24-29. DOI: 10.1080/10717540802481349

Macocinschi, D., Filip, D., Vlad, S.., Oprea, A. M. \& Gafitanu, C. A. (2012). Characterization of a poly(ether urethane)-based controlled release membrane system for delivery of ketoprofen. Applied Surface Science, 259, 416-423. DOI: 10.1016/j.apsusc.2012.07.060

Mathew, S. T., Gayathri, Devi, S., Prasanth, V. \& Vinod, B. (2009). Formulation and in vitro-in vivo evaluation of ketoprofen-loaded albumin microspheres for intramuscular administration. Journal of Microencapsulation, 26(5), 456-469. DOI: $10.1080 / 02652040802420367$

Mbah, C., Ogbonna, J., Nzekwe, I., Ugwu, G., Ezeh, R., Builders, P., Attama, A., Adikwu, M., Ofoefule, S. (2021). Nanovesicle formulation enhances anti-inflammatory and safe use of piroxicam. Pharmaceutical Nanotechnology, 9(3), 177-190. DOI: $10.2174 / 2211738509666210129151844$.

Melendez, O. H. I., Diaz, R. P., Alvarez-Lorenzo, C., Concheiro, A. \& Bucio, E. (2014). Binary graft modification of polypropylene for antiinflammatory drug-device combo products. Journal of Pharmaceutical Sciences, 103(4), 1269-1277. DOI: 10.1002/jps.23903

Morgado, P. I., Miguel, S. P., Correia, I. J. \& Aguiar-Ricardo, A. (2017). Ibuprofen loaded PVA/chitosan membranes: a highly efficient strategy towards an improved skin wound healing. Carbohydrate Polymers, 159, 136-145. DOI: 10.1016/j.carbpol.2016.12.029 
Nayak, A. K. \& Pal, D. (2011). Development of pHsensitive tamarind seed polysaccharide-alginate composite beads for controlled diclofenac sodium delivery using response surface methodology. International Journal of Biological Macromolecules, 49(4), 784-793. DOI: 10.1016/j.ijbiomac.2011.07.013

Paavola, A., Bernards, C. M. \& Rosenberg, P. H. (2016). Controlled release ibuprofen poloxamer gel for epidural use - a pharmacokinetic study using microdialysis in pigs. European Journal of Pharmaceutics and Biopharmaceutics, 108, 180186. DOI: 10.1016/j.ejpb.2016.09.006

Pang, J., Luan, Y., Li, F., Cai, X., Du, J. \& Li, Z. (2011). Ibuprofen-loaded poly(lactic-coglycolic acid) films for controlled drug release. International Journal of Nanomedicine, 6, 659665. DOI: 10.2147/IJN.S17011

Park, E. S., Cui, Y., Yun, B. J., Ko, I. J. \& Chi, S. C. (2005). Transdermal delivery of piroxicam using microemulsions. Archives of Pharmacal Research, 28(2), 243-248. DOI: 10.1007/BF02977723

Park, J. W., Yun, Y. P., Park, K., Lee, J. Y., Kim, H. J., Kim, S. E. \& Song, H. R. (2016). Ibuprofenloaded porous microspheres suppressed the progression of monosodium iodoacetate-induced osteoarthritis in a rat model. Colloids and Surfaces, 147, 265-273. DOI: 10.1016/j.colsurfb.2016.07.050

Park, J. Y., Lee, I. H. ((2010). Controlled release of ketoprofen from electrospun porous polylactic acid (PLA) nanofibers. Journal of Polymer Research, 18, 1287-1291. DOI: 10.1007/s10965010-9531-0

Paukkonen, H., Kunnari, M., Lauren, P., Hakkarainen, T., Auvinen, V. V., Oksanen, T., Koivuniemi, R., Yliperttula, M. \& Laaksonen, T. (2017). Nanofibrillar cellulose hydrogels and reconstructed hydrogels as matrices for controlled drug release. International Journal of Pharmaceutics, 532(1), 269-280. DOI: 10.1016/j.ijpharm.2017.09.002

Petit, A., Sandker, M., Muller, B., Meyboom, R., van Midwoud, P., Bruin, P., Redout, E. M., Versluijs-Helder, M., van der Lest, C.H. A., Buwalda, S. J., de Leede, L.G. J., Vermonden, T., Kok, R. J., Weinans, H. \& Hennink, W. E. (2014). Release behavior and intra-articular biocompatibility of celecoxib-loaded acetylcapped PCLA-PEG-PCLA thermogels. Biomaterials, 35(27), 7919-7928. DOI: 10.1016/j.biomaterials.2014.05.064

Piao, Z. Z., Lee, M. K. \& Lee, B. J. (2008). Colonic release and reduced intestinal tissue damage of coated tablets containing naproxen inclusion complex. International Journal of
Pharmaceutics, 350(1), 205-211. DOI: 10.1016/j.ijpharm.2007.08.044

Rahmani Del Bakhshayesh, A., Akbarzadeh, A., Alihemmati, A., Tayefi Nasrabadi, H., Montaseri, A., Davaran, S., Abedelahi, A. (2020). Preparation and characterization of novel anti-inflammatory biological agents based on piroxicam-loaded poly- $\varepsilon$-caprolactone nanoparticles for sustained NSAID delivery. Drug Delivery, 27(1), 269-282. DOI: 10.1080/10717544.2020.1716881

Rodrigues, M. R., Lanzarini, C. M. \& Ricci-Junior, E. (2011). Preparation, in vitro characterization and in vivo release of naproxen loaded in polycaprolactone nanoparticles. Pharmaceutical Development and Technology, 16(1), 12-21. DOI: $10.3109 / 10837450903460475$

Saidi, L., Vilela, C., Oliveira, H., Silvestre, A. J. D. \& Freire, C. S. R. (2017). Poly(N-methacryloyl glycine)/nanocellulose composites as $\mathrm{pH}$ sensitive systems for controlled release of diclofenac. Carbohydrate Polymers, 169, 357365. DOI: 10.1016/j.carbpol.2017.04.030

Salmoria, G. V., Paggi, R. A., Castro, F., Roesler, C.R. M., Moterle, D. \& Kanis, L. A. (2016). Development of PCL/Ibuprofen tubes for peripheral nerve regeneration. Procedia CIRP, 49, 193-198. DOI: 10.1016/j.procir.2015.11.014

Sanli, O., Ay, N. \& Isklan, N. (2007). Release characteristics of diclofenac sodium from poly(vinyl alcohol)/sodium alginate and poly(vinyl alcohol)-graftedpoly(acrylamide)/sodium alginate blend beads. European Journal of Pharmaceutics and Biopharmaceutics, 65(2), 204-214. DOI: 10.1016/j.ejpb.2006.08.004

Seetharaman, G., Kallar, A. R., Vijayan, V. M., Muthu, J. \& Selvam, S. (2017). Design, preparation and characterization of $\mathrm{pH}-$ responsive prodrug micelles with hydrolyzable anhydride linkages for controlled drug delivery. Journal of Colloid and Interface Science, 492, 61-72. DOI: 10.1016/j.jcis.2016.12.070

Semalty, A., Semalty, M., Singh, D. \& Rawat, M. (2010). Development and characterization of aspirin-phospholipid complex for improved drug delivery. International Journal of Pharmaceutical Sciences and Nanotechnology, 3(2), 940-947. DOI: 10.37285/ijpsn.2010.3.2.7

Sharma, P. (2008). Proniosome based drug delivery system of piroxicam. African Journal of Pharmacy and Pharmacology, 2(9), 184-190.

Sharma, R. K., Lalita, Singh, A. P. \& Chauhan, G. S. (2014). Grafting of GMA and some comonomers onto chitosan for controlled release of diclofenac sodium. International Journal of Biological 
Macromolecules, 64, 368-376. DOI:

10.1016/j.ijbiomac.2013.12.028

Sharma, S. \& Pawar, A. (2006). Low density multiparticulate system for pulsatile release of meloxicam. International Journal of Pharmaceutics, 313(1), 150-158. DOI: 10.1016/j.ijpharm.2006.02.001

Shende, P. K., Gaud, R. S., Bakal, R. \& Patil, D. (2015). Effect of inclusion complexation of meloxicam with $\beta$-cyclodextrin- and $\beta$ cyclodextrin-based nanosponges on solubility, in vitro release and stability studies. Colloids and Surfaces B: Biointerfaces, 136,105-110. DOI: 10.1016/j.colsurfb.2015.09.002

Shi, Y., Liu, Z., Yang, Y., Xu, X., Li, Y. \& Li, T. (2017). Design of poly(mPEGMA-coMAA) hydrogel-based mPEG-b-PCL nanoparticles for oral meloxicam delivery. Materials Science and Engineering C: Materials for Biological Applications, 76, 975-984. DOI:

10.1016/j.msec.2017.03.163

Sidney, L. E., Heathman, T.R. J., Britchford, E. R., Abed, A., Rahman, C. V. \& Buttery, L. D. K. (2015). Investigation of localized delivery of diclofenac sodium from poly(D,L-lactic acid- coglycolic acid)/poly(ethylene glycol) scaffolds using an in vitro osteoblast inflammation model. Tissue Engineering Part A, 21(1-2), 362-373. DOI: $10.1089 /$ ten.TEA.2014.0100

Sousa, C. T., Nunes, C., Proenca, M. P., Leitao, D. C., Lima, J. R. S., Araujo, J. P. \& Lucio, M. (2012). pH sensitive silica nanotubes as rationally designed vehicles for NSAIDs delivery. Colloids and Surfaces B: Biointerfaces, 94, 288-295. DOI:

10.1016/j.colsurfb.2012.02.003

Subramanian, N., Ray, S., Ghosal, S. K., Bhadra, R. \& Moulik, S. P. (2004). Formulation design of self-microemulsifying drug delivery systems for improved oral bioavailability of celecoxib. Biological and Pharmaceutical Bulletin, 27(12), 1993-1999. DOI: 10.1248/bpb.27.1993

Sulistio, A., Reyes-Ortega, F., D’Souza, A. M., Ng, S. M. Y., Valade, D., Quinn, J. F., Donohue, A. C., Mansfeld, F., Blencowe, A., Qiao, G., Prankerd, R., Quirk, S., Whittaker, M. R., Davis, T. P. \& Tait, R. J. (2017). Precise control of drug loading and release of an NSAID-polymer conjugate for long term osteoarthritis intraarticular drug delivery. Journal of Materials Chemistry B, 5(31), 6221-6226. DOI: 10.1039/c7tb01518f

Swamy, P., Areefulla, S., Shirs, S., Smitha, G. \& Prashanth, B. (2007). Orodispersible tablets of meloxicam using disintegrant blends for improved efficacy. Indian Journal of
Pharmaceutical Sciences, 69(6), 836-841. DOI: 10.4103/0250-474X.39448

Taepaiboon, P., Rungsardthong, U. \& Supaphol, P. (2006). Drug-loaded electrospun mats of poly(vinyl alcohol) fibres and their release characteristics of four model drugs.

Nanotechnology, 17(9), 2317-2329. DOI: 10.1088/0957-4484/17/9/041

Tkalec, G., Knez, Z. \& Novak, Z. (2016). pH sensitive mesoporous materials for immediate or controlled release of NSAID. Microporous and Mesoporous Mater, 224, 190-200. DOI: 10.1016/j.micromeso.2015.11.048

Tuncay, M., Calis, S., Kas, H., Ercan, M., Peksoy, I. \& Hincal A. (2000). In vitro and in vivo evaluation of diclofenac sodium loaded album in microspheres. Journal of Microencapsulation, 17(2), 145-155. DOI: 10.1080/026520400288382

Thakkar, H., Sharma, R. K., Mishra, A. K., Chuttani, K. \& Murthy, R. R. (2005). Albumin microspheres as carriers for the antiarthritic drug celecoxib. AAPS PharmSciTech, 6(1), E65-E73. DOI: $10.1208 / \mathrm{pt} 060112$

Thakkar, H., Sharma, R., Mishra, A., Chuttani, K. \& Murthy, R. (2004). Efficacy of chitosan microspheres for controlled intra-articular delivery of celecoxib in inflamed joints. Journal of Pharmacy and Pharmacology, 56(9), 10911099. DOI: 10.1211/0022357044166

Thanoo, B., Sunny, M. \& Jayakrishnan, A. (1993). Oral sustained-release drug delivery systems using polycarbonate microspheres capable of floating on the gastric fluid. Journal of Pharmacy and Pharmacology, 45(1), 21-24. DOI: $10.1111 / \mathrm{j} .2042-7158.1993 . t b 03672 . x$

Thing, M., Agardh, L., Larsen, S., Rasmussen, R., Pallesen, J., Mertz, N., Kristensen, J., Hansen, M., Ostergaard, J. \& Larsen, C. S. (2014). A prodrug approach involving in situ depot formation to achieve localized and sustained action of diclofenac after joint injection. Journal of Pharmaceutical Sciences, 103(12), 40214029. DOI: 10.1002/jps. 24221

Valenta, C., Wanka, M. \& Heidlas, J. (2000). Evaluation of novel soya-lecithin formulations for dermal use containing ketoprofen as a model drug. Journal of Controlled Release, 63(1), 165173. DOI: 10.1016/s0168-3659(99)00199-6

Vergote, G., Vervaet, C., Van Driessche, I., Hoste, S., De Smedt, S., Demeester, J., Jain, R., Ruddy, S. \& Remon, J. P. (2002). In vivo evaluation of matrix pellets containing nanocrystalline ketoprofen. International Journal of Pharmaceutics, 240(1), 79-84. DOI: 10.1016/s0378-5173(02)00114-x

Veronese, F. M., Marsilio, F., Caliceti, P., De Filippis, P., Giunchedi, P. \& Lora, S. (1998). 
Polyorganophosphazene microspheres for drug release: polymer synthesis, microsphere preparation, in vitro and in vivo naproxen release. Journal of Controlled Release, 52(3), 227-237. DOI: 10.1016/s0168-3659(97)00098-9

Villalba, B. T., Ianiski, F. R., Vogt, A. G., Pinz, M. P., Reis, A. S., Vaucher, R. A., Soares, M. P., Wilhelm, E. A. \& Luchese, C. (2016). Polymeric nanocapsules as a technological alternative to reduce the toxicity caused by meloxicam in mice. Regulatory Toxicology and Pharmacology, 81(1), 316-321. DOI: 10.1016/j.yrtph.2016.09.023

Vyas, S. P., Singh, R. \& Asati, R. (1995). Liposomally encapsulated diclofenac for sonophoresis induced systemic delivery. Journal of Microencapsulation, 12(2), 149-154. DOI: 10.3109/02652049509015285

Wang, S. H., Liang, Z. H. \& Zeng, S. (2007). Monitoring release of ketoprofen enantiomers from biodegradable poly(D,L-lactide-coglycolide) injectable implants. International Journal of Pharmaceutics, 337(1-2), 102-108. DOI: 10.1016/j.ijpharm.2006.12.031

Wu, C., Quan, J., Xie, J., Branford-White, C., Zhu, L., Yu, Y. \& Wang, Y. (2010). Preparation and controlled release of degradable polymeric ketoprofen-saccharide conjugates. Polymer Bulletin, 67, 593-608. DOI: 10.1007/s00289010-0409-4
Yamada, T., Onishi, H. \& Machida, Y. (2001). Sustained release ketoprofen microparticles with ethylcellulose and carboxymethylethylcellulose. Journal of Controlled Release, 75(3), 271-282. DOI: 10.1016/s0168-3659(01)00399-6

Yar, M., Farooq, A., Shahzadi, L., Khan, A. S., Mahmood, N., Rauf, A., Chaudhry, A. A. \& Ur Rehman, I. (2016). Novel meloxicam releasing electrospun polymer/ceramic reinforced biodegradable membranes for periodontal regeneration applications. Materials Science and Engineering, 64, 148-156. DOI: 10.1016/j.msec.2016.03.072

Yuan, Y., Li, S. M., Mo, F. K. \& Zhong, D. F. (2006). Investigation of microemulsion system for transdermal delivery of meloxicam. International Journal of Pharmaceutics, 321(1), 117-123. DOI: 10.1016/j.ijpharm.2006.06.021

Yüksel, N., Karataş, A., Özkan, Y., Savaşer, A., Özkan, S. A. \& Baykara, T. (2003). Enhanced bioavailability of piroxicam using Gelucire 44/14 and Labrasol: in vitro and in vivo evaluation. European Journal of Pharmaceutics and Biopharmaceutics, 56(3), 453-459. DOI: 10.1016/s0939-6411(03)00142-5

Zhang, Y., Cun, D., Kong, X. \& Fang, L. (2014). Design and evaluation of a novel transdermal patch containing diclofenac and teriflunomide for rheumatoid arthritis therapy. Asian Journal of Pharmaceutical Sciences, 9(5), 251-259. DOI: 10.1016/j.ajps.2014.07.007 